Review

\title{
Oxidant Stress and Signal Transduction in the Nervous System with the PI 3-K, Akt, and mTOR Cascade
}

\author{
Kenneth Maiese $^{1,2,3, *}$, Zhao Zhong Chong ${ }^{1,3}$, Shaohui Wang ${ }^{1,3}$ and Yan Chen Shang ${ }^{1,3}$ \\ 1 Laboratory of Cellular and Molecular Signaling, Newark, NJ 07101, USA; \\ E-Mails: zzchong@yahoo.com (Z.Z.C.);wsh2078@gmail.com (S.W.); \\ 2 \\ ycshang2000@yahoo.com (Y.C.S.) \\ Cancer Institute of New Jersey, New Brunswick, NJ 08903, USA \\ 3 \\ New Jersey Health Sciences University, 205 South Orange Avenue, Newark, NJ 07101, USA \\ * Author to whom correspondence should be addressed: E-Mail: wntin75@yahoo.com.
}

Received: 8 October 2012; in revised form: 19 October 2012 / Accepted: 19 October 2012 /

Published: 26 October 2012

\begin{abstract}
Oxidative stress impacts multiple systems of the body and can lead to some of the most devastating consequences in the nervous system especially during aging. Both acute and chronic neurodegenerative disorders such as diabetes mellitus, cerebral ischemia, trauma, Alzheimer's disease, Parkinson's disease, Huntington's disease, and tuberous sclerosis through programmed cell death pathways of apoptosis and autophagy can be the result of oxidant stress. Novel therapeutic avenues that focus upon the phosphoinositide 3-kinase (PI 3-K), Akt (protein kinase B), and the mammalian target of rapamycin (mTOR) cascade and related pathways offer exciting prospects to address the onset and potential reversal of neurodegenerative disorders. Effective clinical translation of these pathways into robust therapeutic strategies requires intimate knowledge of the complexity of these pathways and the ability of this cascade to influence biological outcome that can vary among disorders of the nervous system.
\end{abstract}

Keywords: Akt; Alzheimer's disease; apoptosis; autophagy; diabetes mellitus; Huntington's disease; mammalian target of rapamycin (mTOR); oxidative stress; Parkinson's disease; phosphoinositide 3-kinase (PI 3-K); SIRT1 


\section{Introduction}

Oxidative stress through the generation of reactive oxygen species (ROS) can severely impact the nervous system and related pathways that control immune function and cellular metabolism during aging. ROS are formed through superoxide free radicals, hydrogen peroxide, singlet oxygen, nitric oxide (NO), and peroxynitrite [1-3]. ROS can result in mitochondrial dysfunction, the loss of DNA integrity, and the misfolding of proteins that promote cell injury in the nervous system $[2,4,5]$. Antioxidant systems in the body that include catalase, superoxide dismutase, glutathione peroxidase, and vitamins $\mathrm{C}, \mathrm{D}, \mathrm{E}$, and $\mathrm{K}$ limit the production of ROS to non-toxic levels [6-13]. However, excessive production of ROS or impairments in the endogenous antioxidant system can lead to oxidative stress and cell death through DNA degradation, mitochondrial dysfunction, and protein misfolding [2,3,14-17]. Oxidative stress can lead to cognitive loss [14,18-20], Alzheimer's disease (AD) [1,13,20-24], Huntington's disease (HD) [25-31], Parkinson's disease [1,9,26,32-39], epilepsy [25,26,28,40-43], and acute injury such as during stroke and trauma [44-54]. Oxidative stress also modulates inflammatory cell function [55-60] and alters cellular metabolism that leads to complications of diabetes mellitus [5,61-71]. Although multiple cellular pathways are impacted during oxidative stress in the nervous system, the kinase cascade that involves phosphoinositide 3-kinase (PI 3-K), protein kinase B (Akt), and the mammalian target of rapamycin (mTOR) offers exciting prospects for the development of new treatment strategies since these pathways are closely integrated and directly affect both acute and chronic neurological disorders [25,55,72-74]. Greater understanding of these pathways can foster novel as well as safe clinical treatment avenues for disorders of the nervous system.

\section{Oxidant Stress and Cellular Injury}

\subsection{Cellular Survival and Demise during Neurodegeneration}

Oxidative stress pathways that involve the PI 3-K, Akt, and mTOR cascade can lead to cellular injury through the processes of apoptosis and autophagy [39,75] (Figure 1). During neurodegenerative disorders, apoptosis may be a significant contributor of cell dysfunction and loss. Apoptotic DNA fragmentation [76] and caspase activation is present [77] in the brains of patients with Alzheimer's disease (AD). Alzheimer's disease models have demonstrated apoptotic proteins in the brain [78]. Apoptotic neuronal nuclei and caspase 3 have been identified in the postmortem nigra of Parkinson's disease (PD) patients [79]. For immune mediated cells of the brain, loss of microglia can occur through apoptotic cell death $[80,81]$. In regards to autophagy, this process may play a dual role that can either protect cell survival or potentiate cell injury. During oxidative stress, autophagy can lead to cell death in cerebral astrocytes [82], in cortical neurons [83], in spinal cord motor neurons [84], in purkinje neurons [85], and in sympathetic neurons [86]. Other toxins such as glutamate, potassium deprivation, and staurosporine also lead to autophagy and cell death [85]. During metabolic disease, apoptosis can lead to vascular complications, impair endothelial cell survival, destroy immune mediated cells, inhibit wound repair, and injure neurons $[1,87,88]$. However, autophagy and apoptosis may have similar outcomes that are intertwined. The agent methamphatamine leads to cell death through both apoptosis and autophagy by inhibiting the disassociation of the "apoptotic-autophagic complex" Bcl-2/Beclin 1 
complex [89]. Autophagy and apoptosis also may have opposing roles. Apoptosis may conversely require the inhibition of autophagy [90] or apoptotic neuronal cell death may be independent of the onset of autophagy [91]. Under some conditions, autophagy can offer cytoprotection during neurodegenerative disorders [92,93]. Autophagy may be necessary to protect against neuronal cell loss and $\alpha$-synuclein toxicity in PD [92]. Mutation of $\alpha$-synuclein and accumulation of wild-type $\alpha$-synuclein in dopaminergic neurons have been associated with progression of Parkinson's disease [94]. Autophagy is necessary for the clearance of aberrant $\alpha$-synuclein in neurons since inhibition of this autophagic pathway leads to accumulation of high molecular weight and detergent insoluble $\alpha$-synuclein and neurotoxicity [94]. Mutant $\alpha$-synuclein, which is poorly internalized into lysosomes, also is degraded by macroautophagy [92]. During metabolic disease such as diabetes mellitus (DM), autophagy may be necessary to remove misfolded proteins and eliminate non-functioning mitochondria in $\beta$-cells to prevent $\beta$-cell dysfunction and the onset of DM [95]. Exercise in mice has been shown to initiate autophagy and regulate glucose homeostasis [96]. However, the generation of advanced glycation end products (AGEs) during DM also may lead to autophagy that contributes to vascular smooth muscle proliferation, atherosclerosis [97], and potential cardiomyopathy [64]. The elevation of free fatty acids in cell models of DM suggest that fatty acids may be necessary to activate autophagy in beta cells through endoplasmic reticulum stress [98].

\subsection{Apoptotic Early and Late Phases}

Apoptosis consists of two distinct components that involve genomic DNA degradation and the loss of plasma membrane lipid asymmetry [2]. The loss of asymmetry of membrane phosphatidylserine (PS) distribution is an early component of apoptosis that can be reversible [99]. A later event, the cleavage of genomic DNA into fragments can occur once a cell has been committed to die [100]. Once initiated, genomic DNA degradation usually is not reversible. Enzymes responsible for DNA degradation include the acidic cation independent endonuclease (DNase II), cyclophilins, and the $97 \mathrm{kDa}$ magnesium-dependent endonuclease. Three separate endonuclease activities exist in neurons that include a constitutive acidic cation-independent endonuclease, a constitutive calcium/magnesium-dependent endonuclease, and an inducible magnesium dependent endonuclease [22]. Both membrane PS exposure and genomic DNA degradation are considered to be the outcomes of a series of activation of nucleases and proteases that occurs late during apoptosis $[1,88]$. Exposure of membrane PS residues during oxidative stress can occur with sepsis, ischemia, vascular clot formation, and $\beta$-amyloid deposition [101-103]. The early phase of apoptosis can tag cells with membrane PS residues to alert inflammatory cells to engulf and remove injured cells [104,105]. For this to occur such as during periods of oxidative stress, inflammatory cells increase their expression of the membrane phosphatidylserine receptor (PSR) [106-108]. To promote cell survival, modulation of inflammatory cell activation is necessary, since removal of temporarily injured cells expressing membrane PS residues can lead to the loss of functional cells [109,110]. 
Figure 1. Signal transduction pathways of the PI 3-K, Akt, and mTOR cascade. During oxidative stress, multiple pathways are affected that involve PI 3-K, Akt, and mTOR that ultimately interface with programmed cell death pathways of apoptosis and autophagy. Activation of phosphoinositide 3 kinase (PI 3-K), such as by tropic factors that include erythropoietin can promote the production of phosphatidylinositide $(3,4)$-biphosphate (PI-3,4- $\left.\mathrm{P}_{2}\right)$ and phosphatidylinositide $(3,4,5)$-triphosphate (PI-3,4,5- $\left.\mathrm{P}_{3}\right)$ that recruits Akt to the plasma membrane. This recruitment activates phosphoinositide dependent kinase 1 (PDK1) and PDK2, leading to Akt phosphorylation. Akt activity can be blocked by the phosphatase and tensin homolog deleted from chromosome 10 (PTEN), SH2 domain-containing inositol phosphatase (SHIP), and carboxyl-terminal modulator protein (CTMP). Akt activity can be enhanced by the T cell leukemia/lymphoma 1 (TCL1) and $90 \mathrm{kDa}$ heat shock protein (Hsp90) that can inhibit protein phosphatase 2A (PP2A). Akt can activate mTORC1 through phosphorylating TSC2 and disrupting the interaction between TSC2 and TSC1. Akt may also activate mTORC1 through I-kappaB kinase (IKK). IKK $\alpha$ associates with Raptor and IKK $\beta$ that can phosphorylate TSC1 and suppress TSC1 and its interaction with TSC2. In addition, Akt can directly phosphorylate proline rich Akt substrate $40 \mathrm{kDa}$ (PRAS40) to reduce PRAS40 binding to regulatory associated protein of mTOR (Raptor) and thereby activate mTORC1. Upon activation, mTORC1 phosphorylates its downstream targets $\mathrm{p} 70$ ribosome S6 kinase (p70S6K) to phosphorylate pro-apoptotic protein $\mathrm{BAD}$ and increase the expression of $\mathrm{Bcl}-2 / \mathrm{Bcl}-\mathrm{x}_{\mathrm{L}}$ which functions as an anti-apoptotic protein. mTORC1 activation also inhibits autophagic proteins autophagy related gene 13 (Atg13) and UNC-51 like kinase 1/2(ULK1/2) through phosphorylation to prevent autophagy. Rapamycin, an inhibitor of mTOR, can prevent this process and foster autophagy. mTOR signaling inhibits apoptosis though activation of Akt that inhibits

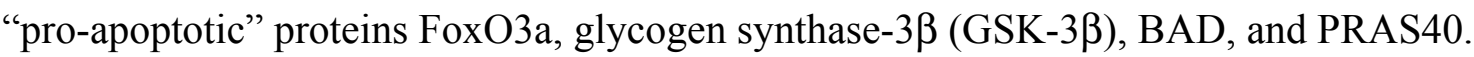

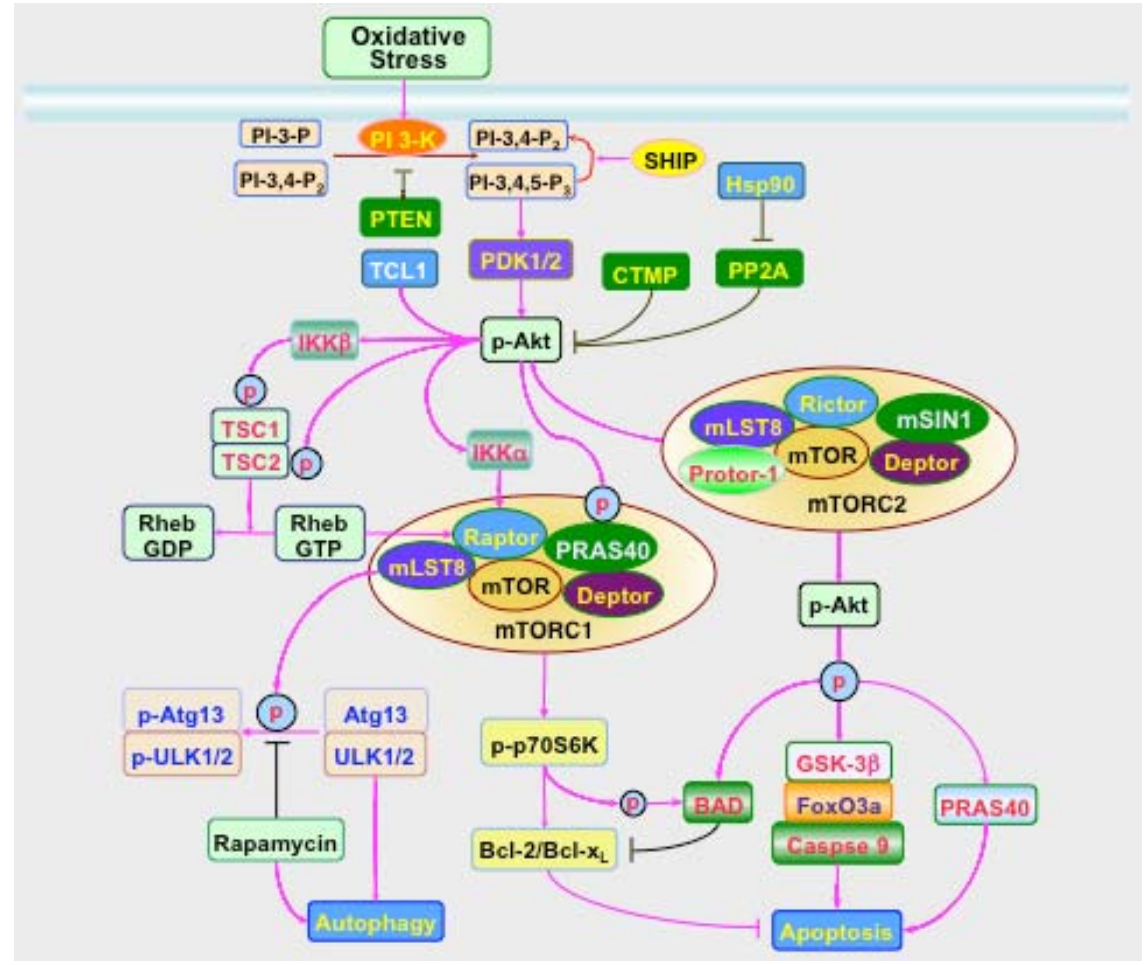




\subsection{The Sub-Constructs of Autophagy}

In contrast to apoptosis, autophagy has three different categories known as microautophagy, macroautophagy, and chaperone-mediated autophagy [99,111,112]. Macroautophagy consists of the degradation of cytoplasmic material and the sequestration of the cytoplasmic protein and organelles into autophagosomes. Autophagosomes fuse with lysosomes for degradation and are then recycled for future cellular processes [113]. Microautophagy represents the sequestration of cytoplasmic components by invagination of the lysosomal membrane. Vesicles subsequently formed are transferred to the lumen of the lysosomes for digestion. In chaperone-mediated autophagy, the cytoplasmic component is transported by cytosolic chaperones to the receptors on the lysosomal membranes for translocation across lysosomal membranes into the lumen.

In yeast, thirty-three autophagic related genes (Atg) have been identified. Of this family of genes, Atg1 and Atg13 are associated with the PI 3-K, Akt, and mTOR cascade [114-116]. In yeast, Atg13 (also known as Apg13) is phosphorylated through a Tor dependent mechanism, leading its release from Atg1 and a reduction in Atg1 activity. The Tor kinase was first isolated in Saccharomyces cerevisiae through the analysis of rapamycin toxicity using rapamycin-resistant TOR mutants in yeast that resulted in the identification of the yeast genes TOR1 and TOR2 that encode two isoforms in yeast Tor1 and Tor2 [117]. In mammals, a single gene FRAP1 encodes mTOR [99,118]. Upon starvation or Tor inhibition, Atg13 is dephosphorylated, binds to, and activates Atg1, leading to autophagosome formation [116]. In mammals, a similar regulation of autophagy through mTOR also exists. Two mammalian homologues of Atg1, UNC-51 like kinase 1 (ULK1) and ULK2, have been identified [119-121]. Mammalian Atg13 binds to ULK1, ULK2, and FIP200 (FAK-family interacting protein of $200 \mathrm{kDa}$ ) to activate ULKs and facilitate the phosphorylation of FIP200 by ULKs [122,123]. Similar to TOR in yeast, mTOR phosphorylates the mammalian homologue Atg13 and the mammalian Atg1 homologues ULK1 and ULK2 to block autophagy [123]. The focal adhesion kinase family interacting protein of $200 \mathrm{kDa}$ (FIP200) has been identified as a ULK binding protein. FIP200 and $\operatorname{Atg} 13$ are vital for the stability and activation of ULK1. Mammalian Atg13 binds to ULK1/2 and FIP200 to activate ULKs and facilitate the phosphorylation of FIP200 by ULKs [123]. mTOR activation prevents autophagy in mammalian cells through inhibition of the ULK-Atg13-FIP200 complex by phosphorylating Atg13 and ULKs. In the absence of mTOR activity, dephosphorylation of ULKs and Atg13 ensues leading to the induction of autophagy [122,123].

\section{Signal Transduction and Cell Survival with PI 3-K, Akt, and mTOR}

\subsection{PI 3-K and PDK}

Receptor tyrosine kinase (RTK) and the G protein-coupled receptor (CPCR) are required for PI 3-K activation. Following activation, PI 3-K phosphorylates membrane lipids and mediates the transition of Akt from the cytosol to the plasma membrane by promoting the binding of Akt to PI-3,4- $\mathrm{P}_{2}$ and $\mathrm{PI}-3,4,5-\mathrm{P}_{3}$ through the plectrin homology $(\mathrm{PH})$ domain (Figure 1). Akt is then phosphorylated on the residues of serine ${ }^{473}$ and threonine ${ }^{308}$ by phosphoinositide dependent kinase (PDK) PDK1 and PDK2. PDK1 is responsible for phosphorylating Akt at threonine ${ }^{308}$ [124]. PDK1 contains a C-terminal PH domain that PI-3, 4, 5- $\mathrm{P}_{3}$ can recruit PDK1 to the cell membrane and bind to the $C$-terminal HM 
domain of Akt. PDK1 cannot directly phosphorylate Akt on serine ${ }^{473}$, but phosphorylation of Akt on serine $^{473}$ is necessary for the full activation of Akt. PDK2 like kinases, such as integrin-linked kinase, DNA dependent protein kinase, $\mathrm{PKC} \beta$, and $\mathrm{mTORC} 2$, have been identified to promote Akt phosphorylation on serine ${ }^{473}$ [125]. In contrast, the phosphatase and tensin homolog deleted from chromosome 10 (PTEN), which specifically dephosphorylates PI-3,4-P 2 and PI-3,4,5-P 3 at the D3 position can block PI 3-K signaling and inhibit Akt activation.

\subsection{Akt}

A number of pathways can influence Akt activity during oxidative stress [126-130]. The $90 \mathrm{kDa}$ heat shock protein (Hsp90) that is involved in modulating oxidative stress in cells [131] can increase Akt activity through the inhibition of inhibiting protein phosphatase 2A (PP2A). In addition, the T cell leukemia/lymphoma 1 (TCL1) protein binds to the $\mathrm{PH}$ domain of Akt to increase Akt activity (Figure 1). In regards to down-regulation of Akt activity, the carboxyl-terminal modulator protein (CTMP) binds to the carboxyl-terminal regulatory domain of Akt 1 at the plasma membrane to prevent Akt1 from phosphorylation. The src homology 2 ( $\mathrm{SH} 2)$ domain-containing inositol phosphatase (SHIP) is an inositol 5' phosphatase that dephosphorylates inositides and phosphoinositides on the 5'-position [55]. Both SHIP1 and SHIP2 can negatively regulate the activity of Akt. PI-3, 4, 5-P 3 are transformed into PI-3, 4- $\mathrm{P}_{2}$ that is less potent than PI-3, 4, 5- $\mathrm{P}_{3}$ to recruit Akt. The $\mathrm{SH} 2$ domains containing protein-tyrosine phosphatases SHP1 and SHP2 also modulate the activity of PI 3-K. SHP1 associates with the p85 subunit of PI 3-K to negatively regulate the activation of PI 3-K. SHP2 can be necessary for agents that promote cell differentiation to lead to the activation of PI 3-K and Akt [132].

\section{3. $m$ TOR}

In relation to mTOR, which also is known as mechanistic target of rapamycin and FK506-binding protein 12-rapamycin complex-associated protein 1 (FRAP1), Akt is a strong stimulator of mTORC1 to lead to the activation of mTORC1 [133]. As a component of the PI 3-K related kinase family that is activated through the PI $3-\mathrm{K}$ and Akt, mTOR is a $289-\mathrm{kDa}$ serine/threonine protein kinase that can control transcription, cytoskeleton organization, cellular survival, and cellular metabolism [25,87,99,133-135]. mTOR signaling is dependent upon the protein complexes mTOR Complex 1 (mTORC1) or mTOR Complex 2 (mTORC2) that each contain mTOR (Figure 1). p70 ribosomal S6 kinase (p70S6K) and eukaryotic initiation factor 4E (eIF4E)-binding protein 1 (4EBP1) are downstream targets of mTORC1 [99,136]. Phosphorylation of p70S6K promotes mRNA biogenesis, translation of ribosomal proteins, and cell growth [137,138]. In contrast, phosphorylation of 4EBP1 results in its inactivation. Hypophosphorylated 4EBP1 is active and binds competitively with eukaryotic translation initiation factor 4 gamma (eIF4G) to eukaryotic translation initiation factor 4 epsilon (eIF4E) that regulate translation initiation by interacting with the 5'-mRNA cap structure. The phosphorylation of 4EBP1 by mTORC1 results in its dissociation from eIF4E allowing eIF4G to interact with eIF4E and promotes protein translation $[139,140]$. Tuberous sclerosis complex (TSC) 1 (hamartin)/TSC2 (tuberin) complex is one of the targets of Akt for the modulation of mTORC1 activity. In the absence of Akt, the TSC1/TSC2 complex is a negative regulator of mTORC1. TSC2 functions as a GTPase-activating protein (GAP), converting a small G protein Ras homologue enriched 
in brain (Rheb-GTP) to the inactive GDP-bound form (Rheb-GDP) [141]. Once active, Rheb-GTP can directly interact with Raptor to activate mTORC1 and also regulate the binding of 4EBP1 to mTORC1 [142]. Akt phosphorylates TSC2 on multiple sites that leads to the destabilization of TSC2 and disruption of its interaction with TSC1. The phosphorylation of TSC2 on the residues of serine ${ }^{939}$, serine $^{981}$, and threonine ${ }^{1462}$ can increase its binding to the anchor protein 14-3-3 and lead to the cellular sequestration by 14-3-3, disruption of the TSC1/TSC2 complex, and subsequent activation of Rheb and mTORC1 [143].

The proline rich Akt substrate $40 \mathrm{kDa}$ (PRAS40) and I-kappaB kinase (IKK) also are targets of Akt to control the activation of mTORC1. PRAS40 can be phosphorylated on several residues including serine $^{183}$, serine ${ }^{212}$, serine ${ }^{221}$, and threonine ${ }^{246}[144,145]$. The serine sites are targets of mTOR and the residue of threonine ${ }^{246}$ is the phosphorylation target of Akt. The phosphorylation of PRAS40 leads to its dissociation with Raptor [146] and promotes the binding of PRAS40 to the cytoplasmic docking protein 14-3-3 [147-149]. This removes PRAS40 from interacting with Raptor and facilitates the activation of mTORC1 [150]. Akt also has been shown to promote the activation of mTORC1 through IKK $\alpha$. Loss of IKK $\alpha$ inhibits mTOR activation in Akt-active cells during inactivation of the negative PI 3-K regulator PTEN [151]. Within IKK, IKK $\alpha$ and IKK $\beta$ are catalytic subunits of IKK that possess serine/threonine kinase activity [152]. IKK $\alpha$ regulates mTOR activity by associating with Raptor that is Akt dependent [151]. In addition, IKK $\beta$ can phosphorylate TSC1 on serine ${ }^{487}$ and serine ${ }^{511}$ leading to the suppression of TSC1, disruption of TSC1/TSC2 complex, and the activation of mTORC1 [153]. Phosphorylation of IKK $\beta$ also has been associated with the activation of downstream pathways of mTOR signaling that involve p70S6K [154].

\subsection{Apoptosis and Autophagy in the PI 3-K, Akt, and mTOR Cascade}

The PI 3-K, Akt, and mTOR cascade closely govern cell survival during apoptosis and autophagy in the nervous system (Figure 1). PI 3-K and Akt activation can foster endothelial survival [128,155-161], limit neuronal injury [105,162-168], and block inflammatory cell death [59,81,106-108,169,170], and block neuronal injury [105,162-168]. A number of cellular pathways can be responsible for the activation of PI 3-K and Akt. For example, intracellular calcium release that is controlled by calmodulin activation leads to the association of calcium and calmodulin with the $85 \mathrm{kDa}$ regulatory subunit of PI $3-\mathrm{K}$ to activate Akt and promote neuronal survival $[171,172]$. Other pathways may be mediated through growth factors and cytokines, such as erythropoietin (EPO) [173]. For example, EPO induces the phosphorylation of Akt at serine ${ }^{473}$ to lead to its activation. EPO can protect dorsal root ganglion neurons in animal models of diabetes mellitus with streptozotocin through pathways that activate Akt [174]. EPO relies upon Akt activation in pathways that require sirtuins to maintain cerebral vascular cell survival during oxidative stress [159]. During EPO exposure, Akt is activated that results in the post-translational phosphorylation of forkhead transcription factors, such as FoxO proteins. Once phosphorylated, FoxO is sequestered in the cytoplasm by association with 14-3-3 proteins and transcription of "pro-apoptotic" genes is prevented [175]. Mammalian forkhead transcription factors of the O class (FoxO1, FoxO3, FoxO4, and FoxO6), such as FoxO3a, are intimately involved with cellular survival, metabolism, insulin sensitivity, and oxidative stress [176,177]. Akt limits apoptosis through the phosphorylation of FoxO 
proteins [176,178-181]. Akt phosphorylates the residue of serine ${ }^{253}$ of FoxO3a resulting in its export from the nucleus to the cytoplasm and blocking FoxO3a from activating apoptotic genes. Akt is required for EPO to promote protection such as during glyoxal-advanced glycation end products (AGEs) exposure [167], retinal detachment [182], $\beta$-amyloid (A $\beta$ ) exposure [80,183-185], hypoxia [156,186], and oxidative stress [187-189]. In addition, the downstream targets of Akt include

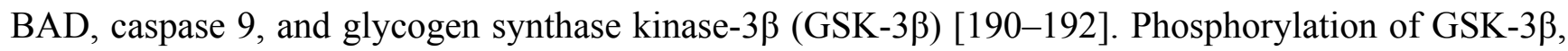
BAD, and caspase 9 by Akt prevents apoptosis and promotes cell longevity pathways $[1,3,18,193]$. Akt can phosphorylate GSK-3 $\beta$ at serine ${ }^{9}$ and inactivate this enzyme, this preventing GSK-3 $\beta$ from initiating an apoptotic pathway. Phosphorylation of Bad at serine ${ }^{136}$ by Akt can result in the inactivation of Bad and prevent neuronal apoptosis [159,194].

Similar to Akt, mTOR can rely upon pathways such as BAD to control apoptosis. mTOR also regulates apoptotic cell death through the mTOR signaling pathways of p70S6K and 4EBP1 $[87,133,195]$. Phosphorylation of BAD leads to the dissociation of BAD from Bcl-2/Bcl- $\mathrm{x}_{\mathrm{L}}$ that prevents apoptotic cell death and increases BAD binding to the cytoplasmic docking protein 14-3-3. Activation of p70S6K also promotes the phosphorylation of BAD to limit apoptotic cell injury [195]. The activation of mTOR and p70S6K may also decrease apoptosis in non-neuronal astrocytes through pathways that can increase "anti-apoptotic" Bcl-2/Bcl- $\mathrm{x}_{\mathrm{L}}$ expression [195]. Growth factors, such as insulin, prevent apoptosis in rat retinal neuronal cells against serum deprivation through activation of mTOR and p70S6K [196]. In addition, over-expression of wild type p70S6K increases cell protection by insulin. In contrast, over-expression of a dominant-negative mutant of p70S6K results in the loss of the ability of insulin to protect neurons [196]. Other growth factors similar to insulin, such as EPO [100,197], also have been reported to be dependent upon mTOR, p70S6K, and 4EBP1 for cytoprotection against apoptosis [145,184,198-200]. In regards to 4EBP1, inhibition of mTOR signaling by small interfering RNA (siRNA) inhibits phosphorylation of both p70S6K and 4EBP1 that results in apoptosis [201]. In the absence of mTOR activity, 4EBP1 has increased binding to eIF4E that can lead to the translation of apoptotic promoting proteins and also initiate autophagy [202].

mTOR also works in conjunction with Akt to offer cellular protection in the nervous system. mTOR and Akt are necessary for the protection of endothelial cells against apoptosis [203] and to prevent cell injury from FoxO3a [155,203]. Inflammatory cells succumb to apoptotic injury during oxidative stress if deprived of Akt and mTOR activation [184,204]. Administration of agents that enhance mTOR and Akt activity can prevent apoptotic dopaminergic neuronal death [205].

Akt also functions to modulate apoptosis through the mTOR signaling pathway of PRAS40. Phosphorylation of PRAS40 by Akt can block the activity of this substrate, lead to its dissociation from mTORC1 to allow mTOR activation, and prevent apoptotic cell injury [147,206,207]. PRAS40 is an important regulatory component for protection in the nervous system. Inhibition of PRAS40 activity can prevent cell death against oxidative stress and A $\beta$ suggesting that PRAS40 may be a critical target to prevent neurodegeneration [147,206]. In addition, PRAS40 appears to be closely aligned with the apoptotic injury cascade since PRAS40 can directly control caspase 3 activation [147].

Under some circumstances such as during chronic disorders of neurodegeneration, inhibition of mTOR activity may be beneficial as opposed to activation of mTOR. Activation of mTOR and mTORC1 signaling can promote cell cycle induction that can be detrimental to post-mitotic neurons. Post-mitotic neurons that attempt to enter the cell cycle during AD do not replicate, but can result in 
apoptotic cell death [208,209]. In studies with amyloid oligomer exposure, neurons can be prevented from entering the cell cycle during the inhibition of mTOR and thus be protected from apoptosis [210]. Furthermore, blockade of the PI 3-K, Akt, and mTOR cascade can lead to the induction of autophagy that may be necessary for cell protection. Under some conditions that involve AD, PD, or HD, induction of autophagy can be cytoprotective. The degree of mTOR activation may be a significant variable in disorders that under some conditions can benefit from precise mTOR activity. During the early phases of autophagy, mTOR activity can be inhibited [211]. However, re-activation of mTOR appears to be required to continue with autophagy as long as elevated levels of mTOR activity do not lead to the eventual blockade of autophagy [212]. This modulation of mTOR with autophagy may be a conserved response in multiple cell systems that is governed by nutrient availability [212].

\section{Clinical Disorders Modulated by PI 3-K, Akt, and mTOR}

\subsection{Diabetes Mellitus in the Nervous System}

Throughout the world, more than 165 million individuals are afflicted with DM and it is expected that close to 400 million individuals by the year of 2030 will suffer from DM. The incidence of obesity in the population throughout the world is increasing at an alarming rate that ultimately leads to metabolic disease and diabetes mellitus (DM) [66]. Recent studies have shown that the duration of obese-years rather than body mass index (BMI) translates into a strong risk for developing DM [213]. Increased weight gain also leads to other disorders that may be a result of metabolic disease, such as coronary artery calcifications and the loss of cognition [68,214]. In younger individuals, impaired glucose tolerance is of significant concern, since those with impaired glucose tolerance have a greater than twice the risk for the development of diabetic complications than individuals with normal glucose tolerance [87,129].

Given the progressive development of DM in the population, elucidation of novel pathways that can regulate the onset and progression of diabetic complications in the nervous system and related cardiovascular pathways would be highly desirable. One signaling pathway that is intimately tied to the PI 3-K, Akt, and mTOR pathway in DM involves sirtuins (Figure 2). Sirtuins are class III $\mathrm{NAD}^{+}$-dependent protein histone deacetylases that are the mammalian homologues of Sir2 of the yeast silent information regulator-2 (Sir2) [1]. Of the seven mammalian homologues of Sir2, SIRT1 has been shown to be protective against cellular injury during DM. SIRT1 activation prevents endothelial senescence during hyperglycemia, blocks atherosclerotic lesions during elevated lipid states, modulates adipocyte differentiation, and prevents endothelial cell apoptosis during experimental diabetes $[1,128,159,215,216]$. SIRT1 also can increase lifespan in higher organisms such as Drosophila and protect cells from oxidative stress [102,217]. Loss of SIRT1 is associated with insulin resistance. Gene deletion or inhibition of SIRT1 impairs insulin signaling by interfering with insulin stimulated insulin receptor phosphorylation and glycogen synthase [218]. In contrast, over-expression of SIRT1 decreases hepatic steatosis and improves insulin sensitivity that leads to improved glucose homeostasis [219]. SIRT1 can increase insulin signaling in insulin-sensitive organs through Akt and PI 3-K [220] and can stimulate glucose-dependent insulin secretion from pancreatic $\beta$ cells by repressing the uncoupling protein (UCP) gene UCP2 [221]. SIRT1 also controls insulin sensitivity 
through the inhibition of tyrosine phosphatase1B (PTP1B). SIRT1 over-expression or SIRT1 activation can reduce both PTP1B mRNA and protein levels during insulin-resistance. However, an increase in PTP1B expression prevents SIRT1 mediated glucose uptake and insulin receptor phosphorylation in response to insulin stimulation [218]. SIRT1 also may improve insulin sensitivity through the regulation of fat mobilization, gluconeogenesis, and inflammation $[1,3,215]$.

Figure 2. Modulation of neurodegenerative disorders through PI 3-K, Akt, mTOR, and associated pathways of SIRT1. Oxidative stress leads to cell injury in multiple neurodegenerative disorders. In Parkinson's disease (PD), oxidative stress can lead to the induction of the stress response protein REDD1 that can inhibit the activation of mTOR. The accumulation of amyloid (A $\beta$ ) during Alzheimer's disease (AD) also can block the activation of mTOR. In AD, retinoblastoma tumor suppressor (RB1) inducible Coiled-Coil 1 (RB1CC1), which functions to activate mTOR, is reduced, contributing to neuronal atrophy in AD. The activation of the downstream target of mTOR, p70 ribosome S6 kinase (p70S6K), by phosphorylation (p) prevents acute neuronal injury during stroke. However, inhibition of mTOR and p70S6K is required to promote autophagy and the clearance of aggregate prone proteins, such as $\alpha$-synuclein, $A \beta$, and Huntingtin to prevent neuronal loss. A fine balance of mTOR activation is necessary in these disorders since mTOR can lead to dyskinesia in PD and activation of p70S6K has been associated with the promotion of the phosphorylation of tau protein contributing to formation of neurofibrillary tangles. During diabetes mellitus (DM), increasing oxidative stress results in insulin resistance, which can be ameliorated by SIRT1. Activation of SIRT1 can increase the secretion of insulin by repressing the mitochondrial uncoupling protein 2 (UCP2), promoting lipolysis, and increasing gluconeogenesis. SIRT1 also can increase insulin sensitivity by inhibiting tyrosine phosphatase 1B (PTP1B). Elevated levels of oxidative stress can reduce insulin sensitivity and enhance the activity of FoxO3a. FoxO3a has multiple roles that can interact with SIRT1 and influence $\beta$ cell function as well as modulate inflammation. SIRT1 can increase FoxO3a activity through deacetylation (dAc). SIRT1 also can activate Akt that decreases the activity of FoxO3a through phosphorylation (p). Enhanced activity of mTOR increases insulin secretion, induces adipogenesis, and inhibits lipolysis that can influence nervous system complications of DM.

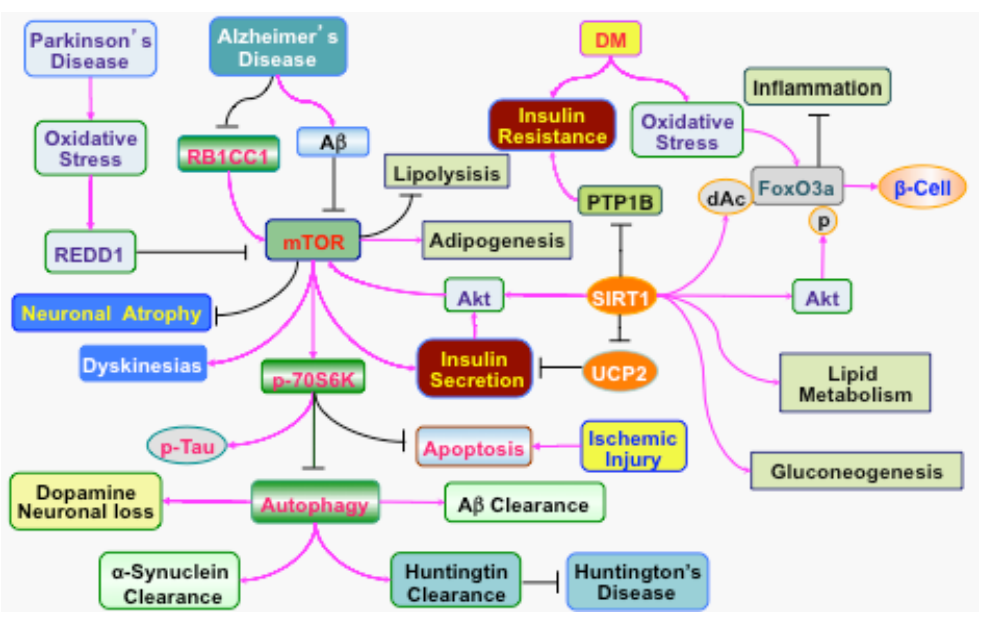


Agents such as EPO increase endogenous SIRT1 activity and foster nuclear subcellular trafficking of SIRT1 [159]. SIRT1 increases Akt activity that is considered to be a principle pathway for cellular proliferation, survival, and for mediating insulin signaling [6,52,55,128,159,222]. SIRT1 activates Akt1 to also control the phosphorylation and subcellular trafficking of FoxO3a [159]. SIRT1 relies upon the Akt pathway for cytoprotection and the subsequent phosphorylation of target genes such as FoxOs [159,220]. However, SIRT1 may control a fine balance over FoxO activity since acetylation of FoxOs also can limit their transcriptional activity. SIRT1 can lead to the deacetylation of FoxOs to increase the activity of these transcription factors [178,181]. Yet, the deacetylation of FoxOs by SIRT1 may ultimately lead to degradation of these transcription factors [223]. SIRT1 also may rely upon the regulation of FoxO transcription factors to protect against inflammation, to promote $\beta$-cell function during DM, and to maintain endothelial survival during oxidative stress [3,181].

Signaling through SIRT1, PI 3-K, and Akt during cell metabolism also is dependent upon mTOR. For example, loss of SIRT1 expression leads to hepatic glucose overproduction, hyperglycemia, products of oxidative stress, and inhibition of the gene encoding Rictor that results in impaired TORC2 and Akt signaling [224]. Under some conditions, SIRT1 and mTOR may have an inverse relationship. SIRT1 can attenuate hepatic steatosis, ameliorate insulin resistance, and restore glucose homeostasis primarily through the inhibition of mTORC1 [219]. SIRT1 also may promote neuronal growth through pathways that inhibit mTOR signaling [225].

Independently, mTOR signaling also may be necessary for maintenance of insulin function. Activation of p70S6K, and inhibition of 4EBP1 in pancreatic $\beta$-cells in murine models of DM, results in improved insulin secretion and resistance to $\beta$-cell streptozotocin toxicity and obesity [226]. However, loss of p70S6K activity with combined loss of the mTORC2 substrate Akt2 results in defects in both insulin action and $\beta$-cell function, suggesting that both mTOR components are required to maintain insulin signaling and prevent DM [227]. Furthermore, mTOR inhibition with rapamycin application leads to insulin resistance, reduces $\beta$-cell function and mass, limits insulin secretion, and results in DM [228]. Loss of mTOR signaling with inhibition of p70S6K also can result in hypoinsulinemia, glucose intolerance, insulin insensitivity to glucose secretion, and a decrease in pancreatic $\beta$-cell size [25,87]. Although inhibition of mTOR can reduce food intake and prevent fat-diet induced obesity in mice, loss of mTOR activity also attenuates glucose uptake and metabolism in skeletal muscle through the prevention of insulin generated Akt activation and alteration in the translocation of glucose transporters to the plasma membrane [127].

mTOR activity also can regulate lipid metabolism. Activation of mTOR may be essential for adipogenesis and adipocyte differentiation [229,230]. Application of rapamycin has been shown to significantly reduce expression of most adipocyte markers including peroxisome proliferators-activated receptor- $\gamma$ (PPAR- $\gamma$ ), adipsin, adipocyte protein 2 (aP2), $\alpha$-adducin (ADD1)/sterol regulatory element-binding protein 1(SREBP1c), and FAS [229]. Rapamycin also prevents intracellular lipid accumulation in 3T3-L1 and 3T3-F442A cells [229]. In addition, activation of mTOR inhibits lipolysis. For example, activation of mTORC1 signaling in 3T3-L1 adipocytes by ectopic expression of Rheb inhibits adipose triglyceride lipase and hormone-sensitive lipase and promotes intracellular accumulation of triglycerides. In contrast, inhibition of mTORC1 signaling by rapamycin or by knockdown of Raptor results in an increase in the expression of lipase and lipolysis [231] and leads to weight loss in gerbil, rats, and humans [228,232]. The ability of mTOR to 
regulate lipid metabolism has been associated with lipin, a magnesium-dependent phosphatidic acid phosphatase. Lipin plays a role in the regulation of fat cell differentiation and triglyceride synthesis [233]. Mutations in the Lpin1 gene result in hepatic steatosis in fld mice, a genetic model of lipodystrophy [234]. Lipin may function downstream of the peroxisome proliferator-activated receptor $\gamma(\mathrm{PPAR} \gamma)$ coactivator 1 alpha $(\mathrm{PGC}-1 \alpha)$ and selectively activates a PGC-1 $\alpha$ mediated fatty acid oxidation and mitochondrial oxidative phosphorylation, suppresses lipogenesis, and lowers circulating lipid levels [87,235]. Activation of mTOR can increase the phosphorylation of lipin and mediate insulin induced lipin phosphorylation, resulting in the release of lipin from intracellular membranes [236].

In the central nervous system, mTOR also has a role in regulating food intake in the hypothalamus. mTOR is expressed ubiquitously in the nervous system. Phosphorylated mTOR and P70S6K has been shown to be expressed in the hippocampus, thalamus, cortex, and paraventricular (PVN) and arcuate (ARC) nuclei of the hypothalamus [237]. The ARC nuclei contain at least two populations of neurons, including orexigenic neurons that express both neuropeptide Y (NPY) and agouti-related peptide (AgRP) and anorexigenic neurons that express proopiomelanocortin (POMC) and cocaine- and amphetamine-regulated transcript (CART). Each of these agents is linked to the regulation of cellular energy homeostasis. mTOR and p70S6K exist in up to $90 \%$ of ARC NPY/AgRP neurons and in approximately $45 \%$ of ARC POMC/CART neurons. Central administration of leucine increases hypothalamic mTOR signaling and decreases food intake and body weight. The hormone leptin increases hypothalamic mTOR activity and inhibition of mTOR signaling has been associated with anorexia [237]. Leptin significantly results in the phosphorylation of p70S6K and p90 ribosomal S6 kinase 1 (RSK1) in mice placed on a low-fat diet and leads to hyperphagia, weight gain, and leptin resistance during diet-induced obesity [238]. Nutrient availability and insulin regulate leptin expression. Yet, mTORC1 also plays a role in leptin expression in adipose cells, since up-regulation of mTORC1 in 3T3-L1 adipocytes via stable expression of either constitutively active Rheb or dominant-negative AMP activated protein kinase (AMPK) results in a significant increase in leptin expression [239]. AMPK can phosphorylate tuberin (TSC2) and inhibit mTORC1 [240].

\subsection{Acute Injury in the Nervous System}

The PI 3-K, Akt, and mTOR pathways play a significant role during acute injury in the nervous system (Figure 2). For example, EPO activates the PI 3-K and Akt pathways to protect neurons, vascular cells, and immune cells during oxidative stress [80,155,156,159,167,169,174,175,182,183,187,200,241,242]. Agents that can increase the expression of Raptor are associated with neuroprotection during hypoxia in invertebrate models of stroke [243]. Furthermore, agents that increase activity of Akt, mTOR, and p70S6K also can reduce cerebral infarct size [244]. Activation of mTOR is necessary in primary cerebral microglia [80,184,204,206] and in neurons [25,147] to prevent apoptotic cell death during oxygen-glucose deprivation. Following acute spinal cord injury, an increase in mTOR expression and p70S6K activity also may be required for functional improvement [245]. Studies with bisperoxovanadium that can enhance the activities of Akt and mTOR have been demonstrated to reduce motor neuron death, increase tissue sparing, and reduce cavity formation after spinal cord 
injury in rats [246]. ATP administration that increases Akt, mTOR, and p70S6K signaling is accompanied by improved locomotor function following spinal cord injury [247]. mTOR in conjunction with other pathways such as signal transducers and activators of transcription (STAT) pathways can foster axonal regeneration [248]. For example, axonal regeneration is increased in adult retinal ganglion cells and in corticospinal neurons following injury paradigms with mTOR activation $[249,250]$.

However, some conditions may require mTOR blockade to promote neuronal protection and autophagy in conjunction with increased activity of the PI 3-K and Akt axis [111]. Inhibition of mTOR and p70S6K activities also improves functional recovery in closed head injury models [251]. Blockade of mTOR has been shown to promote autophagy, inhibit mTOR-mediated inflammation, reduce neural tissue damage, and limit locomotor impairment following spinal cord injury [252]. Inhibition of PTEN (phosphatase and tensin homolog deleted on chromosome 10) that results in enhanced mTOR activity results in increased cerebral infarction [253]. Inhibition of mTOR signaling also prevents cerebral vasospasm and preserves endothelial cell function in animal models of subarachnoid hemorrhage [254].

During disorders of epilepsy that can be a recurrent acute disability, mTOR inhibition may be beneficial. Aberrant or significant mTOR activity is believed to interfere with normal brain function and lead to epilepsy. Inhibition of mTOR activity during kainate-induced epilepsy decreases neuronal cell death, neurogenesis, mossy fiber sprouting, and the development of spontaneous epilepsy [255]. Chronic hippocampal infusion of rapamycin that blocks mTOR signaling also limits mossy fiber sprouting in rat pilocarpine models of temporal lobe epilepsy [256]. mTOR signaling also is considered to be one mechanism for seizure disorders that occur in tuberous sclerosis (TS) [257]. Mutations of TSC1 and TSC2 that lead to hyperactive mTOR result in a high incidence of epilepsy [258]. Early inhibition of mTOR signaling in animal models of TS can prevent astrogliosis and neuronal dysfunction [259].

\subsection{Chronic Neurodegeneration}

Similar to disorders with acute nervous system injury, the temporal course and level of PI 3-K, Akt, and mTOR activation during chronic neurodegenerative disorders that can progress during aging can influence cellular survival and clinical outcome (Figure 2). During disorders such as AD, a minimum level of the PI 3-K, Akt, and mTOR pathway may be required. Since A $\beta$ is toxic to cells [184,260], activation of the PI $3-\mathrm{K}$ and Akt pathways has been shown to prevent A $\beta$ toxicity [103,168,184,261-263]. In regards to mTOR, blockade of mTOR activity may lead to neuronal atrophy in AD. Insufficiency of retinoblastoma tumor suppressor (RB1) inducible Coiled-Coil 1 (RB1CC1) has been observed in the brains of AD patients. In these patients, RB1CC1 appears to be necessary for neurite growth and to maintain mTOR signaling, but the reduced expression of RB1CC1 leads to reduced mTOR activity, neuronal apoptosis, and neuronal atrophy [264]. A decrease in mTOR activity in peripheral lymphocytes also appears to correlate with the progression of $\mathrm{AD}$ [265] and inhibition of mTOR activity has been shown to impair memory consolidation [266]. Loss of mTOR signaling also has been shown to impair long-term potentiation and synaptic plasticity in models of AD [267]. In addition, A $\beta$ can block the activation of mTOR and 
p70S6K in neuroblastoma cells and in lymphocytes of patients with $\mathrm{AD}$ [268]. Activation of mTOR and $\mathrm{p} 70 \mathrm{~S} 6 \mathrm{~K}$ has been shown to prevent cell death during $\mathrm{A} \beta$ exposure in microglia, cells that are necessary for the removal of $\mathrm{A} \beta$ [184].

Additional studies provide further support for the premise that the degree of activity for the PI 3-K, Akt, and mTOR pathways may be an important factor for the treatment of neurodegenerative disorders, such as AD. In fact, some investigations suggest that inhibition of PI 3-K, Akt, and mTOR signaling may be necessary to achieve therapeutic benefit. For example, an increase in the phosphorylated level of Akt substrates, such as mTOR, GSK-3 $\beta$, and tau protein have been observed in AD, suggesting that these substrates may promote AD progression [269]. Hyper-activation of PI 3-K and Akt associated with decreased calmodulin degradation in lymphoblasts from patients with AD also has been suggested as a potential detriment to cell survival [270]. p70S6K activation also has been associated with hyperphosphorylated tau formation and potential neurofibrillary accumulation in AD patients [271]. In addition, mTOR inhibition that can lead to autophagy in murine models of AD has been shown to improve memory and limit A $\beta$ levels [93].

Inhibition of the PI 3-K, Akt, and mTOR pathway also may be necessary for the treatment of HD, an autosomal dominant disorder characterized by the degeneration of striatal GABAergic projecting neurons that result in involuntary movements and cognitive impairment. Activation of autophagy and the inhibition of mTOR are considered vital for the clearing of aggregate-prone proteins in disorders such as HD [272]. HD is the result of neuronal intracellular aggregates of huntingtin protein mutations that produce abnormally expanded polyglutamine in the N-terminal region of the huntingtin gene and lead to neuronal cell death. As a result, inhibition of mTOR signaling that can promote autophagy may represent a potential therapeutic strategy for HD. Blockade of mTOR activity has been demonstrated to enhance autophagic clearance of proteins with long polyglutamines and a polyalanine-expanded protein [273], attenuate huntingtin accumulation and cell death in cell models of HD, and protect against neurodegeneration in a fly model of HD [274]. Small molecular enhancers of rapamycin also have been shown to promote autophagy with both mTOR dependent and independent mechanisms to increase the clearance of a mutant huntingtin fragment in HD cell models [275]. The rapamycin analog CCI-779 also improves behavioral performance and decreases aggregate formation in a mouse model of HD [274]. Yet, some experimental models of HD suggest that inhibition of only mTORC1 may be insufficient to alter autophagy or huntingtin accumulation. The combined inhibition of mTORC1 and mTORC2 is required for autophagy and reductions in huntingtin accumulation, suggesting that multiple components of the mTOR pathway may modulate cell survival in HD [276]. Other studies support this premise to demonstrate that decreased activity of p70S6K protects against early decline in motor performance with beneficial effects on muscle function, but mutant huntingtin levels in the brain are not affected [277]. Prevention of neuronal demise by mTOR may work in concert with growth arrest and DNA damage protein 34 (GADD34). GADD34 leads to the dephosphorylation of TSC2 and induction of autophagy in cell models of HD with increased cell survival during GADD34 over-expression [27].

In PD, a movement disorder characterized by resting tremor, rigidity, and bradykinesia as a result of the loss of dopaminergic neurons in the substantia nigra, mTOR inactivation and promotion of autophagy may preserve dopaminergic neurons. During inhibition of mTOR and the activation of autophagy, the accumulation of toxic $\alpha$-synuclein in transgenic mice is reduced and neurodegeneration 
is decreased in models of PD [278]. Yet, only portions of the PI 3-K, Akt, and mTOR pathway may be necessary for the treatment of PD. Treatment with rapamycin protects neurons that has been shown to be dependent upon Akt activation, but not associated with mTOR signaling [166]. In addition, activation of 4EBP1 during mTOR inhibition can suppress pathologic experimental phenotypes of PD including degeneration of dopaminergic neurons in Drosophila [279].

Other studies indicate that at least some activity of the mTOR pathway is required for neuronal protection in PD. Decreased mTOR activity may lead to neuronal injury in PD through pathways such as autophagy. Inhibition of mTOR signaling during oxidative stress leads to cell death in dopaminergic neurons by enhancing autophagic neuronal death [205]. The stress response protein REDD1 (RTP801), an inhibitor of mTORC1 activity [280], also is up-regulated in dopaminergic neurons in PD patients [281] and can inactivate Akt and mTOR. REDD1 is highly expressed in several cellular models of PD such as treatment with 6-hydroxydopamine (6-OHDA), MPTP, and rotenone [281]. REDD1 is regarded as a potential contributor to neuronal degeneration in PD, since gene silencing of REDD1 is neuroprotective against 6-OHDA [166]. Loss of mTOR activity and the chronic activation of the mTOR pathway 4EBP1 by leucine-rich repeat kinase 2 (LRRK2), a site for dominant mutations $\mathrm{PD}$, is believed to alter protein translation and lead to the loss of dopaminergic neurons [282]. Interestingly, elevated levels of activity in the PI 3-K, Akt, and mTOR pathways can be detrimental in PD. Treatment with derivatives a dopamine, such as L-DOPA, lead to dopamine D1 receptor-mediated activation of mTORC1 resulting in dyskinesia [283].

\section{Conclusions and Perspectives}

Oxidative stress plays a significant role in the pathology of numerous disorders of the nervous system whether they are of acute or chronic origin during aging. Intimately tied to oxidative stress and the pathways that can determine cell survival are PI 3-K, Akt, and mTOR. The PI 3-K, Akt, and mTOR cascade is involved in the modulation of apoptosis, autophagy, disorders of cellular metabolism, acute nervous system injury, and chronic neurodegeneration. Targeting these pathways offers new inroads for the development of novel therapies that can either prevent or reverse the progression of diabetic complications in the nervous system and nervous system dysfunction. New studies suggest that consideration should be given for the modulation of individual components of the PI 3-K, Akt, and mTOR pathway, since neuronal protection in some cases such as those involving PD may be dependent upon one component such as Akt, but not other downstream components such as mTOR [166]. New work is focusing upon agents that can target different Akt classes with the alkyl-lysophospholipids and small molecule inhibitors of Akt. Alternate strategies that consider PDK1 and eIF4E are also under study. In other scenarios, such as with HD, broader aspects of the cascade may be required that can foster the reduction of toxic cellular aggregates [276]. In preclinical studies, modulation of the PI 3-K, Akt, and mTOR cascade can increase radiosensitivity against tumor cell growth and the vascular supply of tumors [284]. In addition, it appears that mTOR signaling components are required to maintain insulin signaling and prevent DM, since loss of p70S6K activity with the combined loss of the mTORC2 substrate Akt2 results in defects in both insulin action and $\beta$-cell function [227]. One must also take into account additional mechanisms that are tied to the PI 3-K, Akt, and mTOR pathways to promote neuroprotection and cellular energy homeostasis, such as 
GADD34 [27], forkhead transcription factors [110,177,178,285], Raf-mitogen activated protein kinases [286], and SIRT1 [1,3,215].

However, modulation of the PI 3-K, Akt, and mTOR cascade, especially during times of activation is not without its concerns. PI 3-K, Akt, and mTOR are cellular proliferative pathways that can promote aggressive tumor growth. As a result, the United States Food and Drug Administration has approved several rapamycin (sirolimus) and rapamycin derivative compounds ("rapalogs") for the treatment of nervous system cancers that include subependymal giant cell astrocytoma associated with tuberous sclerosis (everolimus) and neuroendocrine pancreatic tumors (everolimus) [73,99]. Early clinical trials using everolimus for the treatment of advanced neuroendocrine tumors suggest that progression free survival can be improved [287]. Prevention of PI 3-K and Akt activation also can block medulloblastoma growth [288].

In addition to these considerations, parameters related to the temporal administration of agents that can modulate the PI 3-K, Akt, and mTOR signaling and the pathways of cell death that should be targeted appear to be critical. For example, recent phase III trials in relation to AD suggest that attempts to reduce $A \beta$ toxicity in the brains of patients with $A D$ through immunotherapy with Bapineuzumab or with Solanezumab (LY2062430) may have had limited clinical success as a result of not instituting therapy prior to significant clinical disease presentation or progression. In animal models of TS, early inhibition of mTOR signaling rather than late treatment has been shown to prevent astrogliosis, premature death, and seizures [259]. Early rather than late mTOR inhibition also can reduce plaques, tangles, and loss of cognition in murine models of $\mathrm{AD}$ [289]. Additional work suggests that the duration of activation of PI 3-K, Akt, and mTOR may be a significant factor for influencing cell survival. Inhibition of mTOR can impair long-term potentiation and synaptic plasticity in models of AD [267] and activation of mTOR signaling can block inflammatory cell death during A $\beta$ exposure [184]. Yet, excessive activation of mTOR can lead to dyskinesia patients with PD [283].

In regards to cell death pathways, apoptosis and autophagy appear to have a complex relationship. During toxin exposure that involves methamphetamine, cell death proceeds through apoptosis and autophagy by inhibiting the disassociation of the Bcl-2/Beclin 1 complex [89], an anti-apoptotic protein that blocks autophagy through its inhibitory interaction with Beclin 1 [290]. Autophagy and apoptosis also can have opposing roles. Some studies report that progression of apoptosis may require the inhibition of autophagy [75,90,291]. In relation to nervous system disorders, it remains unclear when pathways such as autophagy may be beneficial. During oxidative stress, autophagy can lead to cell death in cerebral astrocytes [82], in cortical neurons [83], and in spinal cord motor neurons [84]. Activation of the PI 3-K, Akt, mTOR pathway that can block autophagy may be necessary to protect against AGEs and complications of DM with atherosclerosis [97], prevent spinal cord injury [247], and maintain synaptic plasticity [267]. However, autophagy may be necessary during inhibition of mTOR signaling to improve cognitive function, limit $A \beta$ toxicity [93], and clear mutant huntingtin in HD [275]. Over the next several years, further studies that can continue to unravel the cellular pathways governed by the PI 3-K, Akt, and mTOR cascade and the significant biological role this cascade holds in specific disorders of the nervous system will offer the greatest potential to target these pathways for robust treatments against neurodegenerative disorders. 


\section{Acknowledgments}

This research was supported by the following grants to Kenneth Maiese: American Diabetes Association, American Heart Association (National), Bugher Foundation Award, Janssen Neuroscience Award, LEARN Foundation Award, NIH NIEHS, NIH NIA, NIH NINDS, and NIH ARRA.

\section{Conflict of Interest}

The authors declare no conflict of interest.

\section{References}

1. Chong, Z.Z.; Shang, Y.C.; Wang, S.; Maiese, K. SIRT1: New avenues of discovery for disorders of oxidative stress. Expert Opin. Ther. Targets 2012, 16, 167-178.

2. Maiese, K.; Chong, Z.Z.; Hou, J.; Shang, Y.C. Oxidative stress: Biomarkers and novel therapeutic pathways. Exp. Gerontol. 2010, 45, 217-234.

3. Maiese, K.; Chong, Z.Z.; Shang, Y.C.; Wang, S. Translating cell survival and cell longevity into treatment strategies with SIRT1. Rom. J. Morphol. Embryol. 2011, 52, 1173-1185.

4. Jayaram, H.N.; Kusumanchi, P.; Yalowitz, J.A. NMNAT expression and its relation to NAD metabolism. Curr. Med. Chem. 2011, 18, 1962-1972.

5. Yang, H.; Jin, X.; Kei Lam, C.W.; Yan, S.K. Oxidative stress and diabetes mellitus. Clin. Chem. Lab. Med. 2011, 49, 1773-1782.

6. Maiese, K.; Chong, Z.Z.; Hou, J.; Shang, Y.C. The vitamin nicotinamide: Translating nutrition into clinical care. Molecules 2009, 14, 3446-3485.

7. Maiese, K.; Hou, J.; Chong, Z.Z.; Shang, Y.C. Erythropoietin, forkhead proteins, and oxidative injury: biomarkers and biology. TheScientificWorldJournal 2009, 9, 1072-1104.

8. Muley, M.M.; Thakare, V.N.; Patil, R.R.; Kshirsagar, A.D.; Naik, S.R. Silymarin improves the behavioural, biochemical and histoarchitecture alterations in focal ischemic rats: A comparative evaluation with piracetam and protocatachuic acid. Pharmacol. Biochem. Behav. 2012, 102, 286-293.

9. Sun, L.; Gu, L.; Wang, S.; Yuan, J.; Yang, H.; Zhu, J.; Zhang, H. N-acetylcysteine protects against apoptosis through modulation of group I metabotropic glutamate receptor activity. PLoS One 2012, 7, e32503.

10. Suzen, S.; Cihaner, S.S.; Coban, T. Synthesis and comparison of antioxidant properties of indole-based melatonin analogue indole amino acid derivatives. Chem. Biol. Drug Des. 2012, 79, 76-83.

11. Tupe, R.S.; Tupe, S.G.; Agte, V.V. Dietary nicotinic acid supplementation improves hepatic zinc uptake and offers hepatoprotection against oxidative damage. Br. J. Nutr. 2011, 25, 1-9.

12. Wong, D.Z.; Kadir, H.A.; Lee, C.L.; Goh, B.H. Neuroprotective properties of Loranthus parasiticus aqueous fraction against oxidative stress-induced damage in NG108-15 cells. J. Nat. Med. 2012, 66, 544-551. 
13. Zhang, G.; Zhao, Z.; Gao, L.; Deng, J.; Wang, B.; Xu, D.; Liu, B.; Qu, Y.; Yu, J.; Li, J.; et al. Gypenoside attenuates white matter lesions induced by chronic cerebral hypoperfusion in rats. Pharmacol. Biochem. Behav. 2011, 99, 42-51.

14. Cacciatore, I.; Baldassarre, L.; Fornasari, E.; Mollica, A.; Pinnen, F. Recent advances in the treatment of neurodegenerative diseases based on GSH delivery systems. Oxid. Med. Cell. Longevity 2012, 2012, 240146.

15. Escobar, J.; Pereda, J.; Lopez-Rodas, G.; Sastre, J. Redox signaling and histone acetylation in acute pancreatitis. Free Radic. Biol. Med. 2012, 52, 819-837.

16. Lange, C.A.; Bainbridge, J.W. Oxygen sensing in retinal health and disease. Ophthalmologica 2012, 227, 115-131.

17. Wang, J.; Sun, P.; Bao, Y.; Dou, B.; Song, D.; Li, Y. Vitamin E renders protection to PC12 cells against oxidative damage and apoptosis induced by single-walled carbon nanotubes. Toxicol. In Vitro 2012, 26, 32-41.

18. Chong, Z.Z.; Li, F.; Maiese, K. Oxidative stress in the brain: Novel cellular targets that govern survival during neurodegenerative disease. Prog. Neurobiol. 2005, 75, 207-246.

19. Li, R.P.; Wang, Z.Z.; Sun, M.X.; Hou, X.L.; Sun, Y.; Deng, Z.F.; Xiao, K. Polydatin protects learning and memory impairments in a rat model of vascular dementia. Phytomedicine 2012, 19, $677-681$.

20. Maiese, K.; Chong, Z.Z.; Hou, J.; Shang, Y.C. New strategies for Alzheimer's disease and cognitive impairment. Oxid. Med. Cell. Longevity 2009, 2, 279-289.

21. Bajda, M.; Guzior, N.; Ignasik, M.; Malawska, B. Multi-target-directed ligands in Alzheimer's disease treatment. Curr. Med. Chem. 2011, 18, 4949-4975.

22. Chong, Z.Z.; Li, F.; Maiese, K. Stress in the brain: Novel cellular mechanisms of injury linked to Alzheimer's disease. Brain Res. Brain Res. Rev. 2005, 49, 1-21.

23. Maiese, K.; Chong, Z.; Li, F. Reducing Oxidative Stress and Enhancing Neurovascular Longevity during Diabetes Mellitus. In Neurovascular Medicine: Pursuing Cellular Longevity for Healthy Aging; Maiese, K., Ed.; Oxford University Press: New York, NY, USA, 2009; pp. 540-564.

24. Srivastava, S.; Haigis, M.C. Role of sirtuins and calorie restriction in neuroprotection: Implications in Alzheimer's and Parkinson's diseases. Curr. Pharm. Des. 2011, 17, 3418-3433.

25. Chong, Z.Z.; Shang, Y.C.; Zhang, L.; Wang, S.; Maiese, K. Mammalian target of rapamycin: Hitting the bull's-eye for neurological disorders. Oxid. Med. Cell. Longevity 2010, 3, 374-391.

26. Enz, R. Metabotropic glutamate receptors and interacting proteins: Evolving drug targets. Curr. Drug Targets 2012, 13, 145-156.

27. Hyrskyluoto, A.; Reijonen, S.; Kivinen, J.; Lindholm, D.; Korhonen, L. GADD34 mediates cytoprotective autophagy in mutant huntingtin expressing cells via the mTOR pathway. Exp. Cell Res. 2012, 318, 33-42.

28. Maiese, K.; Chong, Z.Z.; Li, F. Driving cellular plasticity and survival through the signal transduction pathways of metabotropic glutamate receptors. Curr. Neurovasc. Res. 2005, 2, 425-446.

29. Nagley, P.; Higgins, G.C.; Atkin, J.D.; Beart, P.M. Multifaceted deaths orchestrated by mitochondria in neurones. Biochim. Biophys. Acta 2010, 1802, 167-185. 
30. Vidal, R.L.; Figueroa, A.; Court, F.A.; Thielen, P.; Molina, C.; Wirth, C.; Caballero, B.; Kiffin, R.; Segura-Aguilar, J.; Cuervo, A.M.; et al. Targeting the UPR transcription factor XBP1 protects against Huntington's disease through the regulation of FoxO1 and autophagy. Hum. Mol. Genet .2012, 21, 2245-2262.

31. Yang, D.; Wang, C.E.; Zhao, B.; Li, W.; Ouyang, Z.; Liu, Z.; Yang, H.; Fan, P.; O’Neill, A.; $\mathrm{Gu}, \mathrm{W}$; et al. Expression of Huntington's disease protein results in apoptotic neurons in the brains of cloned transgenic pigs. Hum. Mol. Genet. 2010, 19, 3983-3994.

32. Al Sweidi, S.; Sanchez, M.G.; Bourque, M.; Morissette, M.; Dluzen, D.; Di Paolo, T. Oestrogen receptors and signalling pathways: Implications for neuroprotective effects of sex steroids in Parkinson's disease. J. Neuroendocrinol. 2012, 24, 48-61.

33. Asaithambi, A.; Kanthasamy, A.; Saminathan, H.; Anantharam, V.; Kanthasamy, A.G. Protein kinase D1 (PKD1) activation mediates a compensatory protective response during early stages of oxidative stress-induced neuronal degeneration. Mol. Neurodegener. 2011, 6, doi:10.1186/1750-1326-6-43.

34. Das, F.; Dey, N.; Venkatesan, B.; Kasinath, B.S.; Ghosh-Choudhury, N.; Choudhury, G.G. High glucose upregulation of early-onset Parkinson's disease protein DJ-1 integrates the PRAS40/TORC1 axis to mesangial cell hypertrophy. Cell. Signal. 2011, 23, 1311-1319.

35. Khan, M.M.; Ahmad, A.; Ishrat, T.; Khan, M.B.; Hoda, M.N.; Khuwaja, G.; Raza, S.S.; Khan, A.; Javed, H.; Vaibhav, K.; et al. Resveratrol attenuates 6-hydroxydopamine-induced oxidative damage and dopamine depletion in rat model of Parkinson's disease. Brain Res. 2010, 1328, 139-151.

36. Kook, Y.H.; Ka, M.; Um, M. Neuroprotective cytokines repress PUMA induction in the 1-methyl-4-phenylpyridinium (MPP(+)) model of Parkinson's disease. Biochem. Biophys. Res. Commun. 2011, 411, 370-374.

37. L'Episcopo, F.; Tirolo, C.; Testa, N.; Caniglia, S.; Morale, M.C.; Deleidi, M.; Serapide, M.F.; Pluchino, S.; Marchetti, B. Plasticity of subventricular zone neuroprogenitors in MPTP (1-Methyl-4-Phenyl-1,2,3,6-Tetrahydropyridine) mouse model of Parkinson's disease involves cross talk between inflammatory and Wnt/beta-Catenin signaling pathways: Functional consequences for neuroprotection and repair. J. Neurosci. 2012, 32, 2062-2085.

38. Maiese, K.; Chong, Z.Z.; Shang, Y.C.; Hou, J. Therapeutic promise and principles: Metabotropic glutamate receptors. Oxid. Med. Cell. Longevity 2008, 1, 1-14.

39. Maiese, K.; Chong, Z.Z.; Shang, Y.C.; Wang, S. Targeting disease through novel pathways of apoptosis and autophagy. Expert Opin. Ther. Targets 2012, in press.

40. Banach, M.; Piskorska, B.; Czuczwar, S.; Borowicz, K. Nitric oxide, epileptic seizures, and action of antiepileptic drugs. CNS Neurol. Disord. Drug Targets 2011, 10, 808-819.

41. O’Dell, C.M.; Das, A.; Wallace, G.t.; Ray, S.K.; Banik, N.L. Understanding the basic mechanisms underlying seizures in mesial temporal lobe epilepsy and possible therapeutic targets: A review. J. Neurosci. Res. 2012, 90, 913-924.

42. Sensi, S.L.; Paoletti, P.; Koh, J.Y.; Aizenman, E.; Bush, A.I.; Hershfinkel, M. The neurophysiology and pathology of brain zinc. J. Neurosci. 2011, 31, 16076-16085. 
43. Talos, D.M.; Sun, H.; Zhou, X.; Fitzgerald, E.C.; Jackson, M.C.; Klein, P.M.; Lan, V.J.; Joseph, A.; Jensen, F.E. The Interaction between early life epilepsy and autistic-like behavioral consequences: A role for the mammalian target of rapamycin (mTOR) pathway. PLoS One 2012, 7, e35885.

44. Beard, R.S., Jr.; Reynolds, J.J.; Bearden, S.E. Metabotropic glutamate receptor 5 mediates phosphorylation of vascular endothelial cadherin and nuclear localization of beta-catenin in response to homocysteine. Vascul. Pharmacol. 2012, 56, 159-167.

45. Bonilla, C.; Zurita, M.; Otero, L.; Aguayo, C.; Rico, M.A.; Vaquero, J. The severity of brain damage determines bone marrow stromal cell therapy efficacy in a traumatic brain injury model. J. Trauma Acute Care Surg. 2012, 72, 1203-1212.

46. Duris, K.; Manaenko, A.; Suzuki, H.; Rolland, W.B.; Krafft, P.R.; Zhang, J.H. $\alpha 7$ Nicotinic acetylcholine receptor agonist PNU-282987 attenuates early brain injury in a perforation model of subarachnoid hemorrhage in rats. Stroke 2011, 42, 3530-3536.

47. Goffus, A.M.; Anderson, G.D.; Hoane, M. Sustained delivery of nicotinamide limits cortical injury and improves functional recovery following traumatic brain injury. Oxid. Med. Cell. Longevity 2010, 3, 145-152.

48. Guo, J.M.; Dong, W.Z.; Liu, A.J.; Cheng, M.H.; Su, D.F. Nicotinamide postpones stroke in stroke-prone spontaneously hypertensive rats. CNS Neurosci. Ther. 2012, 18, 267-268.

49. Lanfranconi, S.; Locatelli, F.; Corti, S.; Candelise, L.; Comi, G.P.; Baron, P.L.; Strazzer, S.; Bresolin, N.; Bersano, A. Growth factors in ischemic stroke. J. Cell. Mol. Med. 2011, $15,1645-1687$.

50. Ma, Y.; Qu, Y.; Fei, Z. Vascular endothelial growth factor in cerebral ischemia. J. Neurosci. Res. 2011, 89, 969-978.

51. Maiese, K.; Chong, Z.Z.; Hou, J.; Shang, Y.C. Erythropoietin and oxidative stress. Curr. Neurovasc. Res. 2008, 5, 125-142.

52. Maiese, K.; Chong, Z.Z.; Li, F.; Shang, Y.C. Erythropoietin: Elucidating new cellular targets that broaden therapeutic strategies. Prog. Neurobiol. 2008, 85, 194-213.

53. Raza, S.S.; Khan, M.M.; Ashafaq, M.; Ahmad, A.; Khuwaja, G.; Khan, A.; Siddiqui, M.S.; Safhi, M.M.; Islam, F. Silymarin protects neurons from oxidative stress associated damages in focal cerebral ischemia: A behavioral, biochemical and immunohistological study in Wistar rats. J. Neurol. Sci. 2011, 309, 45-54.

54. Zhao, L.D.; Wang, J.H.; Jin, G.R.; Zhao, Y.; Zhang, H.J. Neuroprotective effect of Buyang Huanwu decoction against focal cerebral ischemia/reperfusion injury in rats-Time window and mechanism. J. Ethnopharmacol. 2012, 140, 339-344.

55. Chong, Z.Z.; Maiese, K. The Src homology 2 domain tyrosine phosphatases SHP-1 and SHP-2: Diversified control of cell growth, inflammation, and injury. Histol. Histopathol. 2007, 22, 1251-1267.

56. Kato, S.; Aoyama, M.; Kakita, H.; Hida, H.; Kato, I.; Ito, T.; Goto, T.; Hussein, M.H.; Sawamoto, K.; Togari, H.; et al. Endogenous erythropoietin from astrocyte protects the oligodendrocyte precursor cell against hypoxic and reoxygenation injury. J. Neurosci. Res. 2011, 89, 1566-1574. 
57. Kigerl, K.A.; Ankeny, D.P.; Garg, S.K.; Wei, P.; Guan, Z.; Lai, W.; McTigue, D.M.; Banerjee, R.; Popovich, P.G. System x(c)(-) regulates microglia and macrophage glutamate excitotoxicity in vivo. Exp. Neurol. 2012, 233, 333-341.

58. L’Episcopo, F.; Tirolo, C.; Testa, N.; Caniglia, S.; Morale, M.C.; Cossetti, C.; D’Adamo, P.; Zardini, E.; Andreoni, L.; Ihekwaba, A.E.; et al. Reactive astrocytes and Wnt/beta-catenin signaling link nigrostriatal injury to repair in 1-methyl-4-phenyl-1,2,3,6-tetrahydropyridine model of Parkinson's disease. Neurobiol. Dis. 2011, 41, 508-527.

59. Shang, Y.C.; Chong, Z.Z.; Hou, J.; Maiese, K. FoxO3a governs early microglial proliferation and employs mitochondrial depolarization with caspase 3, 8, and 9 cleavage during oxidant induced apoptosis. Curr. Neurovasc. Res. 2009, 6, 223-238.

60. Shang, Y.C.; Chong, Z.Z.; Hou, J.; Maiese, K. Wnt1, FoxO3a, and NF-kappaB oversee microglial integrity and activation during oxidant stress. Cell. Signal. 2010, 22, 1317-1329.

61. Jiang, Y.L.; Ning, Y.; Ma, X.L.; Liu, Y.Y.; Wang, Y.; Zhang, Z.; Shan, C.X.; Xu, Y.D.; Yin, L.M.; Yang, Y.Q. Alteration of the proteome profile of the pancreas in diabetic rats induced by streptozotocin. Int. J. Mol. Med. 2011, 28, 153-160.

62. John, C.M.; Ramasamy, R.; Al Naqeeb, G.; Dhiab Al-Nuaimi, A.H.; Adam, A. Enhanced $\mathrm{CD} 4+\mathrm{CD} 25+$ regulatory $\mathrm{T}$ cells with splenic proliferation and protection against oxidative stress by nicotinamide in gestational diabetes. Curr. Med. Chem. 2012, in press.

63. Kurban, S.; Mehmetoglu, I.; Yerlikaya, H.F.; Gonen, S.; Erdem, S. Effect of chronic regular exercise on serum ischemia-modified albumin levels and oxidative stress in type 2 diabetes mellitus. Endocr. Res. 2011, 36, 116-123.

64. Lee, Y.; Hong, Y.; Lee, S.R.; Chang, K.T. Autophagy contributes to retardation of cardiac growth in diabetic rats. Lab. Anim. Res. 2012, 28, 99-107.

65. Liu, Z.; Stanojevic, V.; Brindamour, L.J.; Habener, J.F. GLP1-derived nonapeptide GLP1(28-36)amide protects pancreatic beta-cells from glucolipotoxicity. J. Endocrinol. 2012, 213, 143-154.

66. Maiese, K.; Chong, Z.Z.; Shang, Y.C.; Hou, J. Novel avenues of drug discovery and biomarkers for diabetes mellitus. J. Clin. Pharmacol. 2011, 51, 128-152.

67. Maiese, K.; Morhan, S.D.; Chong, Z.Z. Oxidative stress biology and cell injury during type 1 and type 2 diabetes mellitus. Curr. Neurovasc. Res. 2007, 4, 63-71.

68. Maiese, K.; Shang, Y.C.; Chong, Z.Z.; Hou, J. Diabetes mellitus: Channeling care through cellular discovery. Curr. Neurovasc. Res. 2010, 7, 59-64.

69. Pang, J.; Xi, C.; Dai, Y.; Gong, H.; Zhang, T.M. Altered expression of base excision repair genes in response to high glucose-induced oxidative stress in HepG2 hepatocytes. Med. Sci. Monit. 2012, 18, BR281-BR285.

70. Tang, L.; Zhang, Y.; Jiang, Y.; Willard, L.; Ortiz, E.; Wark, L.; Medeiros, D.; Lin, D. Dietary wolfberry ameliorates retinal structure abnormalities in $\mathrm{db} / \mathrm{db}$ mice at the early stage of diabetes. Exp. Biol. Med. (Maywood) 2011, 236, 1051-1063.

71. Zengi, A.; Ercan, G.; Caglayan, O.; Tamsel, S.; Karadeniz, M.; Simsir, I.; Harman, E.; Kahraman, C.; Orman, M.; Cetinkalp, S.; et al. Increased oxidative DNA damage in lean normoglycemic offspring of type 2 diabetic patients. Exp. Clin. Endocrinol. Diabetes 2011, 119, $467-471$. 
72. Acquaah-Mensah, G.K.; Taylor, R.C.; Bhave, S.V. PACAP interactions in the mouse brain: Implications for behavioral and other disorders. Gene 2012, 491, 224-231.

73. Benjamin, D.; Colombi, M.; Moroni, C.; Hall, M.N. Rapamycin passes the torch: A new generation of mTOR inhibitors. Nat. Rev. Drug Discov. 2011, 10, 868-880.

74. Hwang, S.K.; Kim, H.H. The functions of mTOR in ischemic diseases. BMB Rep. 2011, 44, 506-511.

75. Maiese, K. The many facets of cell injury: Angiogenesis to autophagy. Curr. Neurovasc. Res. 2012, 9, 83-84.

76. Broe, M.; Shepherd, C.E.; Milward, E.A.; Halliday, G.M. Relationship between DNA fragmentation, morphological changes and neuronal loss in Alzheimer's disease and dementia with Lewy bodies. Acta Neuropathol. 2001, 101, 616-624.

77. Louneva, N.; Cohen, J.W.; Han, L.Y.; Talbot, K.; Wilson, R.S.; Bennett, D.A.; Trojanowski, J.Q.; Arnold, S.E. Caspase-3 is enriched in postsynaptic densities and increased in Alzheimer's disease. Am. J. Pathol. 2008, 173, 1488-1495.

78. Grammas, P.; Tripathy, D.; Sanchez, A.; Yin, X.; Luo, J. Brain microvasculature and hypoxia-related proteins in Alzheimer's disease. Int. J. Clin. Exp. Pathol. 2011, 4, 616-627.

79. Tatton, N.A. Increased caspase 3 and Bax immunoreactivity accompany nuclear GAPDH translocation and neuronal apoptosis in Parkinson's disease. Exp. Neurol. 2000, 166, 29-43.

80. Shang, Y.C.; Chong, Z.Z.; Wang, S.; Maiese, K. Erythropoietin and Wnt1 govern pathways of mTOR, Apaf-1, and XIAP in inflammatory microglia. Curr. Neurovasc. Res. 2011, 8, 270-285.

81. Zhou, X.; Wang, L.; Wang, M.; Xu, L.; Yu, L.; Fang, T.; Wu, M. Emodin-induced microglial apoptosis is associated with TRB3 induction. Immunopharmacol. Immunotoxicol. 2011, 33, 594-602.

82. Qin, A.P.; Liu, C.F.; Qin, Y.Y.; Hong, L.Z.; Xu, M.; Yang, L.; Liu, J.; Qin, Z.H.; Zhang, H.L. Autophagy was activated in injured astrocytes and mildly decreased cell survival following glucose and oxygen deprivation and focal cerebral ischemia. Autophagy 2010, 6, 738-753.

83. Wang, J.Y.; Xia, Q.; Chu, K.T.; Pan, J.; Sun, L.N.; Zeng, B.; Zhu, Y.J.; Wang, Q.; Wang, K.; Luo, B.Y. Severe global cerebral ischemia-induced programmed necrosis of hippocampal CA1 neurons in rat is prevented by 3-methyladenine: A widely used inhibitor of autophagy. J. Neuropathol. Exp. Neurol. 2011, 70, 314-322.

84. Baba, H.; Sakurai, M.; Abe, K.; Tominaga, R. Autophagy-mediated stress response in motor neuron after transient ischemia in rabbits. J. Vasc. Surg. 2009, 50, 381-387.

85. Canu, N.; Tufi, R.; Serafino, A.L.; Amadoro, G.; Ciotti, M.T.; Calissano, P. Role of the autophagic-lysosomal system on low potassium-induced apoptosis in cultured cerebellar granule cells. J. Neurochem. 2005, 92, 1228-1242.

86. Xue, L.; Fletcher, G.C.; Tolkovsky, A.M. Autophagy is activated by apoptotic signalling in sympathetic neurons: An alternative mechanism of death execution. Mol. Cell. Neurosci. 1999, 14, 180-198.

87. Chong, Z.Z.; Maiese, K. Mammalian target of rapamycin signaling in diabetic cardiovascular disease. Cardiovasc. Diabetol. 2012, 11, doi:10.1186/1475-2840-11-45.

88. Troy, C.M.; Akpan, N.; Jean, Y.Y. Regulation of caspases in the nervous system implications for functions in health and disease. Prog. Mol. Biol. Transl. Sci. 2011, 99, 265-305. 
89. Nopparat, C.; Porter, J.E.; Ebadi, M.; Govitrapong, P. The mechanism for the neuroprotective effect of melatonin against methamphetamine-induced autophagy. J. Pineal. Res. 2010, 49, 382-389.

90. Luo, S.; Rubinsztein, D.C. Apoptosis blocks Beclin 1-dependent autophagosome synthesis: An effect rescued by Bcl-xL. Cell Death Differ. 2010, 17, 268-277.

91. Wang, S.; Chong, Z.Z.; Shang, Y.C.; Maiese, K. WISP1 (CCN4) autoregulates its expression and nuclear trafficking of beta-catenin during oxidant stress with limited effects upon neuronal autophagy. Curr. Neurovasc. Res. 2012, 9, 89-99.

92. Spencer, B.; Potkar, R.; Trejo, M.; Rockenstein, E.; Patrick, C.; Gindi, R.; Adame, A.; Wyss-Coray, T.; Masliah, E. Beclin 1 gene transfer activates autophagy and ameliorates the neurodegenerative pathology in alpha-synuclein models of Parkinson's and Lewy body diseases. J. Neurosci. 2009, 29, 13578-13588.

93. Spilman, P.; Podlutskaya, N.; Hart, M.J.; Debnath, J.; Gorostiza, O.; Bredesen, D.; Richardson, A.; Strong, R.; Galvan, V. Inhibition of mTOR by rapamycin abolishes cognitive deficits and reduces amyloid-beta levels in a mouse model of Alzheimer's disease. PLoS One 2010, 5, e9979.

94. Xilouri, M.; Vogiatzi, T.; Vekrellis, K.; Park, D.; Stefanis, L. Abberant alpha-synuclein confers toxicity to neurons in part through inhibition of chaperone-mediated autophagy. PLoS One 2009, 4, e5515.

95. Liu, Y.; Shi, S.; Gu, Z.; Du, Y.; Liu, M.; Yan, S.; Gao, J.; Li, J.; Shao, Y.; Zhong, W.; et al. Impaired autophagic function in rat islets with aging. Age (Dordr) 2012, doi:10.1007/ s11357-012-9456-0.

96. He, C.; Bassik, M.C.; Moresi, V.; Sun, K.; Wei, Y.; Zou, Z.; An, Z.; Loh, J.; Fisher, J.; Sun, Q.; et al. Exercise-induced BCL2-regulated autophagy is required for muscle glucose homeostasis. Nature 2012, 481, 511-515.

97. Hu, P.; Lai, D.; Lu, P.; Gao, J.; He, H. ERK and Akt signaling pathways are involved in advanced glycation end product-induced autophagy in rat vascular smooth muscle cells. Int. J. Mol. Med. 2012, 29, 613-618.

98. Martino, L.; Masini, M.; Novelli, M.; Beffy, P.; Bugliani, M.; Marselli, L.; Masiello, P.; Marchetti, P.; De Tata, V. Palmitate activates autophagy in INS-1E beta-cells and in isolated rat and human pancreatic islets. PLoS One 2012, 7, e36188.

99. Chong, Z.Z.; Shang, Y.C.; Wang, S.; Maiese, K. Shedding new light on neurodegenerative diseases through the mammalian target of rapamycin. Prog. Neurobiol. 2012, in press.

100. Maiese, K.; Chong, Z.Z.; Shang, Y.C.; Wang, S. Erythropoietin: New directions for the nervous system. Int. J. Mol. Sci. 2012, 13, 11102-11129.

101. Aksu, U.; Demirci, C.; Ince, C. The pathogenesis of acute kidney injury and the toxic triangle of oxygen, reactive oxygen species and nitric oxide. Contrib. Nephrol. 2011, 174, 119-128.

102. Balan, V.; Miller, G.S.; Kaplun, L.; Balan, K.; Chong, Z.Z.; Li, F.; Kaplun, A.; VanBerkum, M.F.; Arking, R.; Freeman, D.C.; et al. Life span extension and neuronal cell protection by Drosophila nicotinamidase. J. Biol. Chem. 2008, 283, 27810-27819. 
103. Chong, Z.Z.; Li, F.; Maiese, K. Cellular demise and inflammatory microglial activation during beta-amyloid toxicity are governed by Wnt1 and canonical signaling pathways. Cell. Signal. 2007, 19, 1150-1162.

104. Bailey, T.J.; Fossum, S.L.; Fimbel, S.M.; Montgomery, J.E.; Hyde, D.R. The inhibitor of phagocytosis, $O$-phospho-L-serine, suppresses Muller glia proliferation and cone cell regeneration in the light-damaged zebrafish retina. Exp. Eye Res. 2010, 91, 601-612.

105. Chong, Z.Z.; Kang, J.; Li, F.; Maiese, K. mGluRI targets microglial activation and selectively prevents neuronal cell engulfment through Akt and Caspase dependent pathways. Curr. Neurovasc. Res. 2005, 2, 197-211.

106. Kang, J.Q.; Chong, Z.Z.; Maiese, K. Critical role for Akt1 in the modulation of apoptotic phosphatidylserine exposure and microglial activation. Mol. Pharmacol. 2003, 64, 557-569.

107. Kang, J.Q.; Chong, Z.Z.; Maiese, K. Akt1 protects against inflammatory microglial activation through maintenance of membrane asymmetry and modulation of cysteine protease activity. J. Neurosci. Res. 2003, 74, 37-51.

108. Shang, Y.C.; Chong, Z.Z.; Hou, J.; Maiese, K. The forkhead transcription factor FoxO3a controls microglial inflammatory activation and eventual apoptotic injury through caspase 3. Curr. Neurovasc. Res. 2009, 6, 20-31.

109. Koh, P.O. Nicotinamide attenuates the decrease of astrocytic phosphoprotein PEA-15 in focal cerebral ischemic injury. J. Vet. Med. Sci. 2012, 74, 377-380.

110. Maiese, K.; Chong, Z.Z.; Shang, Y.C. "Sly as a FOXO": New paths with Forkhead signaling in the brain. Curr. Neurovasc. Res. 2007, 4, 295-302.

111. Balduini, W.; Carloni, S.; Buonocore, G. Autophagy in hypoxia-ischemia induced brain injury. J. Matern. Fetal Neonatal Med. 2012, 25, 30-34.

112. Deretic, V.; Jiang, S.; Dupont, N. Autophagy intersections with conventional and unconventional secretion in tissue development, remodeling and inflammation. Trends Cell Biol. 2012, 22, $397-406$.

113. Silva, D.F.; Esteves, A.R.; Oliveira, C.R.; Cardoso, S.M. Mitochondria: The common upstream driver of amyloid-beta and tau pathology in Alzheimer's disease. Curr. Alzheimer Res. 2011, 8, $563-572$.

114. Scott, R.C.; Juhasz, G.; Neufeld, T.P. Direct induction of autophagy by Atg1 inhibits cell growth and induces apoptotic cell death. Curr. Biol. 2007, 17, 1-11.

115. Kabeya, Y.; Kamada, Y.; Baba, M.; Takikawa, H.; Sasaki, M.; Ohsumi, Y. Atg17 functions in cooperation with Atg1 and Atg13 in yeast autophagy. Mol. Biol. Cell 2005, 16, 2544-2553.

116. Kamada, Y.; Funakoshi, T.; Shintani, T.; Nagano, K.; Ohsumi, M.; Ohsumi, Y. Tor-mediated induction of autophagy via an Apg1 protein kinase complex. J Cell Biol. 2000, 150, 1507-1513.

117. Heitman, J.; Movva, N.R.; Hall, M.N. Targets for cell cycle arrest by the immunosuppressant rapamycin in yeast. Science 1991, 253, 905-909.

118. Brown, E.J.; Albers, M.W.; Shin, T.B.; Ichikawa, K.; Keith, C.T.; Lane, W.S.; Schreiber, S.L. A mammalian protein targeted by G1-arresting rapamycin-receptor complex. Nature 1994, 369, 756-758. 
119. Kuroyanagi, H.; Yan, J.; Seki, N.; Yamanouchi, Y.; Suzuki, Y.; Takano, T.; Muramatsu, M.; Shirasawa, T. Human ULK1, a novel serine/threonine kinase related to UNC-51 kinase of Caenorhabditis elegans: cDNA cloning, expression, and chromosomal assignment. Genomics 1998, 51, 76-85.

120. Yan, J.; Kuroyanagi, H.; Kuroiwa, A.; Matsuda, Y.; Tokumitsu, H.; Tomoda, T.; Shirasawa, T.; Muramatsu, M. Identification of mouse ULK1, a novel protein kinase structurally related to C. elegans UNC-51. Biochem. Biophys. Res. Commun. 1998, 246, 222-227.

121. Yan, J.; Kuroyanagi, H.; Tomemori, T.; Okazaki, N.; Asato, K.; Matsuda, Y.; Suzuki, Y.; Ohshima, Y.; Mitani, S.; Masuho, Y.; et al. Mouse ULK2, a novel member of the UNC-51-like protein kinases: unique features of functional domains. Oncogene 1999, 18, 5850-5859.

122. Hosokawa, N.; Sasaki, T.; Iemura, S.; Natsume, T.; Hara, T.; Mizushima, N. Atg101, a novel mammalian autophagy protein interacting with Atg13. Autophagy 2009, 5, 973-979.

123. Jung, C.H.; Jun, C.B.; Ro, S.H.; Kim, Y.M.; Otto, N.M.; Cao, J.; Kundu, M.; Kim, D.H. ULK-Atg13-FIP200 complexes mediate mTOR signaling to the autophagy machinery. Mol. Biol. Cell 2009, 20, 1992-2003.

124. Ding, Z.; Liang, J.; Li, J.; Lu, Y.; Ariyaratna, V.; Lu, Z.; Davies, M.A.; Westwick, J.K.; Mills, G.B. Physical association of PDK1 with AKT1 is sufficient for pathway activation independent of membrane localization and phosphatidylinositol 3 kinase. PLoS One 2010, 5, e9910.

125. Glidden, E.J.; Gray, L.G.; Vemuru, S.; Li, D.; Harris, T.E.; Mayo, M.W. Multiple site acetylation of rictor stimulates mammalian target of rapamycin complex 2 (mTORC2)-dependent phosphorylation of Akt protein. J. Biol. Chem. 2012, 287, 581-588.

126. Chen, J.X.; Tuo, Q.; Liao, D.F.; Zeng, H. Inhibition of protein tyrosine phosphatase improves angiogenesis via enhancing Ang-1/Tie-2 signaling in diabetes. Exp. Diabetes Res. 2012, 2012, 836759.

127. Deblon, N.; Bourgoin, L.; Veyrat-Durebex, C.; Peyrou, M.; Vinciguerra, M.; Caillon, A.; Maeder, C.; Fournier, M.; Montet, X.; Rohner-Jeanrenaud, F.; et al. Chronic mTOR inhibition by rapamycin induces muscle insulin resistance despite weight loss in rats. Br. J. Pharmacol. 2012, 165, 2325-2340.

128. Hou, J.; Chong, Z.Z.; Shang, Y.C.; Maiese, K. Early apoptotic vascular signaling is determined by Sirt1 through nuclear shuttling, forkhead trafficking, bad, and mitochondrial caspase activation. Curr. Neurovasc. Res. 2010, 7, 95-112.

129. Maiese, K.; Chong, Z.Z.; Shang, Y.C. Mechanistic insights into diabetes mellitus and oxidative stress. Curr. Med. Chem. 2007, 14, 1729-1738.

130. Saha, A.K.; Xu, X.J.; Lawson, E.; Deoliveira, R.; Brandon, A.E.; Kraegen, E.W.; Ruderman, N.B. Downregulation of AMPK accompanies leucine- and glucose-induced increases in protein synthesis and insulin resistance in rat skeletal muscle. Diabetes 2010, 59, 2426-2434.

131. Lu, M.J.; Chen, Y.S.; Huang, H.S.; Ma, M.C. Erythropoietin alleviates post-ischemic injury of rat hearts by attenuating nitrosative stress. Life Sci. 2012, 90, 776-784.

132. Koshimizu, T.; Kawai, M.; Kondou, H.; Tachikawa, K.; Sakai, N.; Ozono, K.; Michigami, T. Vinculin functions as regulator of chondrogenesis. J. Biol. Chem. 2012, 287, 15760-15775. 
133. Chong, Z.Z.; Shang, Y.C.; Maiese, K. Cardiovascular disease and mTOR signaling. Trends Cardiovasc. Med. 2011, 21, 151-155.

134. James, M.F.; Stivison, E.; Beauchamp, R.; Han, S.; Li, H.; Wallace, M.R.; Gusella, J.F.; Stemmer-Rachamimov, A.O.; Ramesh, V. Regulation of mTOR complex 2 signaling in neurofibromatosis 2-deficient target cell types. Mol. Cancer Res. 2012, 10, 649-659.

135. Weber, J.D.; Gutmann, D.H. Deconvoluting mTOR biology. Cell Cycle 2012, 11, 236-248.

136. Chong, Z.Z.; Wang, S.; Shang, Y.C.; Maiese, K. Targeting cardiovascular disease with novel SIRT1 pathways. Future Cardiol. 2012, 8, 89-100.

137. Fingar, D.C.; Richardson, C.J.; Tee, A.R.; Cheatham, L.; Tsou, C.; Blenis, J. mTOR controls cell cycle progression through its cell growth effectors S6K1 and 4E-BP1/eukaryotic translation initiation factor 4E. Mol. Cell. Biol. 2004, 24, 200-216.

138. Jastrzebski, K.; Hannan, K.M.; Tchoubrieva, E.B.; Hannan, R.D.; Pearson, R.B. Coordinate regulation of ribosome biogenesis and function by the ribosomal protein S6 kinase, a key mediator of mTOR function. Growth Factors 2007, 25, 209-226.

139. Gingras, A.C.; Kennedy, S.G.; O’Leary, M.A.; Sonenberg, N.; Hay, N. 4E-BP1, a repressor of mRNA translation, is phosphorylated and inactivated by the $\operatorname{Akt}(\mathrm{PKB})$ signaling pathway. Genes Dev. 1998, 12, 502-513.

140. Bhandari, B.K.; Feliers, D.; Duraisamy, S.; Stewart, J.L.; Gingras, A.C.; Abboud, H.E.; Choudhury, G.G.; Sonenberg, N.; Kasinath, B.S. Insulin regulation of protein translation repressor 4E-BP1, an eIF4E-binding protein, in renal epithelial cells. Kidney Int. 2001, 59, $866-875$.

141. Inoki, K.; Li, Y.; Zhu, T.; Wu, J.; Guan, K.L. TSC2 is phosphorylated and inhibited by Akt and suppresses mTOR signalling. Nat. Cell Biol. 2002, 4, 648-657.

142. Sato, T.; Nakashima, A.; Guo, L.; Tamanoi, F. Specific activation of mTORC1 by Rheb G-protein in vitro involves enhanced recruitment of its substrate protein. J. Biol. Chem. 2009, 284, 12783-12791.

143. Cai, S.L.; Tee, A.R.; Short, J.D.; Bergeron, J.M.; Kim, J.; Shen, J.; Guo, R.; Johnson, C.L.; Kiguchi, K.; Walker, C.L. Activity of TSC2 is inhibited by AKT-mediated phosphorylation and membrane partitioning. J. Cell Biol. 2006, 173, 279-289.

144. Oshiro, N.; Takahashi, R.; Yoshino, K.; Tanimura, K.; Nakashima, A.; Eguchi, S.; Miyamoto, T.; Hara, K.; Takehana, K.; Avruch, J.; et al. The proline-rich Akt substrate of $40 \mathrm{kDa}$ (PRAS40) is a physiological substrate of mammalian target of rapamycin complex 1. J. Biol. Chem. 2007, 282, 20329-20339.

145. Wang, L.; Harris, T.E.; Lawrence, J.C., Jr. Regulation of proline-rich Akt substrate of $40 \mathrm{kDa}$ (PRAS40) function by mammalian target of rapamycin complex 1 (mTORC1)-mediated phosphorylation. J. Biol. Chem. 2008, 283, 15619-15627.

146. Sancak, Y.; Thoreen, C.C.; Peterson, T.R.; Lindquist, R.A.; Kang, S.A.; Spooner, E.; Carr, S.A.; Sabatini, D.M. PRAS40 is an insulin-regulated inhibitor of the mTORC1 protein kinase. Mol. Cell. 2007, 25, 903-915.

147. Chong, Z.Z.; Shang, Y.C.; Wang, S.; Maiese, K. PRAS40 is an integral regulatory component of erythropoietin mTOR signaling and cytoprotection. PLoS One 2012, 7, e45456. 
148. Kovacina, K.S.; Park, G.Y.; Bae, S.S.; Guzzetta, A.W.; Schaefer, E.; Birnbaum, M.J.; Roth, R.A. Identification of a proline-rich Akt substrate as a 14-3-3 binding partner. J. Biol. Chem. 2003, 278, 10189-10194.

149. Vander Haar, E.; Lee, S.I.; Bandhakavi, S.; Griffin, T.J.; Kim, D.H. Insulin signalling to mTOR mediated by the Akt/PKB substrate PRAS40. Nat. Cell Biol 2007, 9, 316-323.

150. Wang, L.; Harris, T.E.; Roth, R.A.; Lawrence, J.C., Jr. PRAS40 regulates mTORC1 kinase activity by functioning as a direct inhibitor of substrate binding. J. Biol. Chem. 2007, 282, 20036-20044.

151. Dan, H.C.; Adli, M.; Baldwin, A.S. Regulation of mammalian target of rapamycin activity in PTEN-inactive prostate cancer cells by I kappa B kinase alpha. Cancer Res. 2007, 67, 6263-6269.

152. Zandi, E.; Rothwarf, D.M.; Delhase, M.; Hayakawa, M.; Karin, M. The IkappaB kinase complex (IKK) contains two kinase subunits, IKK $\alpha$ and IKK $\beta$, necessary for I $\mathrm{KB}$ phosphorylation and NF- $\kappa$ B activation. Cell 1997, 91, 243-252.

153. Lee, D.F.; Kuo, H.P.; Chen, C.T.; Hsu, J.M.; Chou, C.K.; Wei, Y.; Sun, H.L.; Li, L.Y.; Ping, B.; Huang, W.C.; et al. IKK beta suppression of TSC1 links inflammation and tumor angiogenesis via the mTOR pathway. Cell 2007, 130, 440-455.

154. Yen, C.J.; Izzo, J.G.; Lee, D.F.; Guha, S.; Wei, Y.; Wu, T.T.; Chen, C.T.; Kuo, H.P.; Hsu, J.M.; Sun, H.L.; et al. Bile acid exposure up-regulates tuberous sclerosis complex 1/mammalian target of rapamycin pathway in Barrett's-associated esophageal adenocarcinoma. Cancer Res. 2008, 68, 2632-2640.

155. Chong, Z.Z.; Hou, J.; Shang, Y.C.; Wang, S.; Maiese, K. EPO relies upon novel signaling of Wnt1 that requires Akt1, FoxO3a, GSK-3beta, and beta-Catenin to foster vascular integrity during experimental diabetes. Curr. Neurovasc. Res. 2011, 8, 103-120.

156. Chong, Z.Z.; Kang, J.Q.; Maiese, K. Erythropoietin is a novel vascular protectant through activation of Akt1 and mitochondrial modulation of cysteine proteases. Circulation 2002, 106, 2973-2979.

157. Chong, Z.Z.; Kang, J.Q.; Maiese, K. AKT1 drives endothelial cell membrane asymmetry and microglial activation through Bcl-xL and caspase 1, 3, and 9. Exp. Cell Res. 2004, 296, 196-207.

158. Hou, J.; Chong, Z.Z.; Shang, Y.C.; Maiese, K. FoxO3a governs early and late apoptotic endothelial programs during elevated glucose through mitochondrial and caspase signaling. Mol. Cell. Endocrinol. 2010, 321, 194-206.

159. Hou, J.; Wang, S.; Shang, Y.C.; Chong, Z.Z.; Maiese, K. Erythropoietin employs cell longevity pathways of SIRT1 to foster endothelial vascular integrity during oxidant stress. Curr. Neurovasc. Res. 2011, 8, 220-235.

160. Mannell, H.K.; Pircher, J.; Chaudhry, D.I.; Alig, S.K.; Koch, E.G.; Mettler, R.; Pohl, U.; Krotz, F. ARNO regulates VEGF-dependent tissue responses by stabilizing endothelial VEGFR-2 surface expression. Cardiovasc. Res. 2012, 93, 111-119.

161. Su, K.H.; Shyue, S.K.; Kou, Y.R.; Ching, L.C.; Chiang, A.N.; Yu, Y.B.; Chen, C.Y.; Pan, C.C.; Lee, T.S. $\beta$ Common receptor integrates the erythropoietin signaling in activation of endothelial nitric oxide synthase. J. Cell. Physiol. 2011, 226, 3330-3339. 
162. Chen, T.; Zhang, L.; Qu, Y.; Huo, K.; Jiang, X.; Fei, Z. The selective mGluR5 agonist CHPG protects against traumatic brain injury in vitro and in vivo via ERK and Akt pathway. Int. J. Mol. Med. 2012, 29, 630-636.

163. Chong, Z.Z.; Lin, S.H.; Maiese, K. The NAD+ precursor nicotinamide governs neuronal survival during oxidative stress through protein kinase $\mathrm{B}$ coupled to FOXO3a and mitochondrial membrane potential. J. Cereb. Blood Flow Metab. 2004, 24, 728-743.

164. Chong, Z.Z.; Shang, Y.C.; Hou, J.; Maiese, K. Wnt1 neuroprotection translates into improved neurological function during oxidant stress and cerebral ischemia through AKT1 and mitochondrial apoptotic pathways. Oxid. Med. Cell. Longevity 2010, 3, 153-165.

165. Komandirov, M.A.; Knyazeva, E.A.; Fedorenko, Y.P.; Rudkovskii, M.V.; Stetsurin, D.A.; Uzdensky, A.B. On the role of phosphatidylinositol 3-kinase, protein kinase b/Akt, and glycogen synthase kinase-3 $\beta$ in photodynamic injury of crayfish neurons and glial cells. J. Mol. Neurosci. 2011, 45, 229-235.

166. Malagelada, C.; Jin, Z.H.; Jackson-Lewis, V.; Przedborski, S.; Greene, L.A. Rapamycin protects against neuron death in in vitro and in vivo models of Parkinson's disease. J. Neurosci. 2010, 30, 1166-1175.

167. Shen, J.; Wu, Y.; Xu, J.Y.; Zhang, J.; Sinclair, S.H.; Yanoff, M.; Xu, G.; Li, W.; Xu, G.T. ERKand Akt-dependent neuroprotection by erythropoietin (EPO) against glyoxal-AGEs via modulation of Bcl-xL, Bax, and BAD. Invest. Ophthalmol. Vis. Sci. 2010, 51, 35-46.

168. Zeng, K.W.; Wang, X.M.; Ko, H.; Kwon, H.C.; Cha, J.W.; Yang, H.O. Hyperoside protects primary rat cortical neurons from neurotoxicity induced by amyloid beta-protein via the $\mathrm{PI} 3 \mathrm{~K} / \mathrm{Akt} / \mathrm{Bad} / \mathrm{Bcl}(\mathrm{XL})$-regulated mitochondrial apoptotic pathway. Eur. J. Pharmacol. 2011, $672,45-55$.

169. Li, F.; Chong, Z.Z.; Maiese, K. Microglial integrity is maintained by erythropoietin through integration of Akt and its substrates of glycogen synthase kinase-3beta, beta-catenin, and nuclear factor-kappaB. Curr. Neurovasc. Res. 2006, 3, 187-201.

170. Pineda, D.; Ampurdanes, C.; Medina, M.G.; Serratosa, J.; Tusell, J.M.; Saura, J.; Planas, A.M.; Navarro, P. Tissue plasminogen activator induces microglial inflammation via a noncatalytic molecular mechanism involving activation of mitogen-activated protein kinases and Akt signaling pathways and AnnexinA2 and Galectin-1 receptors. Glia 2012, 60, 526-540.

171. Perez-Garcia, M.J.; Cena, V.; de Pablo, Y.; Llovera, M.; Comella, J.X.; Soler, R.M. Glial cell line-derived neurotrophic factor increases intracellular calcium concentration. Role of calcium/calmodulin in the activation of the phosphatidylinositol 3-kinase pathway. J. Biol. Chem. 2004, 279, 6132-6142.

172. Xu, J.; Zhang, Q.G.; Li, C.; Zhang, G.Y. Subtoxic N-methyl-D-aspartate delayed neuronal death in ischemic brain injury through TrkB receptor- and calmodulin-mediated PI-3K/Akt pathway activation. Hippocampus 2007, 17, 525-537.

173. Maiese, K. The challenges for drug development: Cytokines, genes, and stem cells. Curr. Neurovasc. Res. 2012, 9, 231-232.

174. Chattopadhyay, M.; Walter, C.; Mata, M.; Fink, D.J. Neuroprotective effect of herpes simplex virus-mediated gene transfer of erythropoietin in hyperglycemic dorsal root ganglion neurons. Brain 2009, 132, 879-888. 
175. Chong, Z.Z.; Maiese, K. Erythropoietin involves the phosphatidylinositol 3-kinase pathway, 14-3-3 protein and FOXO3a nuclear trafficking to preserve endothelial cell integrity. $\mathrm{Br}$. $\mathrm{J}$. Pharmacol. 2007, 150, 839-850.

176. Maiese, K.; Chong, Z.Z.; Shang, Y.C.; Hou, J. A "FOXO" in sight: Targeting FoxO proteins from conception to cancer. Med. Res. Rev. 2009, 29, 395-418.

177. Storz, P. Forkhead homeobox type O transcription factors in the responses to oxidative stress. Antioxid. Redox Signaling 2011, 14, 593-605.

178. Kousteni, S. FoxO1, the transcriptional chief of staff of energy metabolism. Bone 2012, 50, 437-443.

179. Lam, E.W.; Shah, K.; Brosens, J.J. The diversity of sex steroid action: The role of micro-RNAs and FOXO transcription factors in cycling endometrium and cancer. J. Endocrinol. 2012, 212, 13-25.

180. Lappas, M.; Permezel, M. The anti-inflammatory and antioxidative effects of nicotinamide, a vitamin $\mathrm{B}(3)$ derivative, are elicited by $\mathrm{FoxO} 3$ in human gestational tissues: Implications for preterm birth. J. Nutr. Biochem. 2011, 22, 1195-1201.

181. Maiese, K.; Chong, Z.Z.; Shang, Y.C. OutFOXOing disease and disability: The therapeutic potential of targeting FoxO proteins. Trends Mol. Med. 2008, 14, 219-227.

182. Xie, Z.; Chen, F.; Wu, X.; Zhuang, C.; Zhu, J.; Wang, J.; Ji, H.; Wang, Y.; Hua, X. Effects of supplemental erythropoietin on its receptor expression and signal transduction pathways in rat model of retinal detachment. Curr. Eye Res. 2012, 37, 138-144.

183. Ma, R.; Xiong, N.; Huang, C.; Tang, Q.; Hu, B.; Xiang, J.; Li, G. Erythropoietin protects PC12 cells from beta-amyloid(25-35)-induced apoptosis via PI3K/Akt signaling pathway. Neuropharmacology 2009, 56, 1027-1034.

184. Shang, Y.C.; Chong, Z.Z.; Wang, S.; Maiese, K. Prevention of beta-amyloid degeneration of microglia by erythropoietin depends on Wnt1, the PI 3-K/mTOR pathway, Bad, and Bcl-xL. Aging (Albany NY) 2012, 4, 187-201.

185. Sun, Z.K.; Yang, H.Q.; Pan, J.; Zhen, H.; Wang, Z.Q.; Chen, S.D.; Ding, J.Q. Protective effects of erythropoietin on tau phosphorylation induced by beta-amyloid. J. Neurosci. Res. 2008, 86, 3018-3027.

186. Kilic, E.; Kilic, U.; Soliz, J.; Bassetti, C.L.; Gassmann, M.; Hermann, D.M. Brain-derived erythropoietin protects from focal cerebral ischemia by dual activation of ERK-1/-2 and Akt pathways. FASEB J. 2005, 19, 2026-2028.

187. Chong, Z.Z.; Kang, J.Q.; Maiese, K. Erythropoietin fosters both intrinsic and extrinsic neuronal protection through modulation of microglia, Akt1, Bad, and caspase-mediated pathways. Br. $J$. Pharmacol. 2003, 138, 1107-1118.

188. Dzietko, M.; Felderhoff-Mueser, U.; Sifringer, M.; Krutz, B.; Bittigau, P.; Thor, F.; Heumann, R.; Buhrer, C.; Ikonomidou, C.; Hansen, H.H. Erythropoietin protects the developing brain against $N$-methyl-D-aspartate receptor antagonist neurotoxicity. Neurobiol. Dis. 2004, 15, 177-187.

189. Um, M.; Lodish, H.F. Antiapoptotic effects of erythropoietin in differentiated neuroblastoma SH-SY5Y cells require activation of both the STAT5 and AKT signaling pathways. J. Biol. Chem. 2006, 281, 5648-5656. 
190. Chong, Z.Z.; Lin, S.H.; Li, F.; Maiese, K. The sirtuin inhibitor nicotinamide enhances neuronal cell survival during acute anoxic injury through Akt, Bad, PARP, and mitochondrial associated "anti-apoptotic" pathways. Curr. Neurovasc. Res. 2005, 2, 271-285.

191. Li, F.; Chong, Z.Z.; Maiese, K. Cell life versus cell longevity: The mysteries surrounding the $\mathrm{NAD}(+)$ precursor nicotinamide. Curr. Med. Chem. 2006, 13, 883-895.

192. Maiese, K.; Li, F.; Chong, Z.Z. Erythropoietin in the brain: Can the promise to protect be fulfilled? Trends Pharmacol. Sci. 2004, 25, 577-583.

193. Wang, S.; Chong, Z.Z.; Shang, Y.C.; Maiese, K. Wnt1 inducible signaling pathway protein 1 (WISP1) blocks neurodegeneration through phosphoinositide 3 kinase/Akt1 and apoptotic mitochondrial signaling involving Bad, Bax, Bim, and Bcl-xL. Curr. Neurovasc. Res. 2012, 9, 20-31.

194. Koh, P.O. Nicotinamide attenuates the ischemic brain injury-induced decrease of Akt activation and Bad phosphorylation. Neurosci. Lett. 2011, 498, 105-109.

195. Pastor, M.D.; Garcia-Yebenes, I.; Fradejas, N.; Perez-Ortiz, J.M.; Mora-Lee, S.; Tranque, P.; Moro, M.A.; Pende, M.; Calvo, S. mTOR/S6 kinase pathway contributes to astrocyte survival during ischemia. J. Biol. Chem. 2009, 284, 22067-22078.

196. Wu, X.; Reiter, C.E.; Antonetti, D.A.; Kimball, S.R.; Jefferson, L.S.; Gardner, T.W. Insulin promotes rat retinal neuronal cell survival in a p70S6K-dependent manner. J. Biol. Chem. 2004, 279, 9167-9175.

197. Maiese, K.; Li, F.; Chong, Z.Z. New avenues of exploration for erythropoietin. JAMA 2005, 293, 90-95.

198. Galan-Moya, E.M.; Le Guelte, A.; Lima Fernandes, E.; Thirant, C.; Dwyer, J.; Bidere, N.; Couraud, P.O.; Scott, M.G.; Junier, M.P.; Chneiweiss, H.; et al. Secreted factors from brain endothelial cells maintain glioblastoma stem-like cell expansion through the mTOR pathway. EMBO Rep. 2011, 12, 470-476.

199. Marfia, G.; Madaschi, L.; Marra, F.; Menarini, M.; Bottai, D.; Formenti, A.; Bellardita, C.; Di Giulio, A.M.; Carelli, S.; Gorio, A. Adult neural precursors isolated from post mortem brain yield mostly neurons: an erythropoietin-dependent process. Neurobiol. Dis. 2011, 43, 86-98.

200. Sanghera, K.P.; Mathalone, N.; Baigi, R.; Panov, E.; Wang, D.; Zhao, X.; Hsu, H.; Wang, H.; Tropepe, V.; Ward, M.; et al. The PI3K/Akt/mTOR pathway mediates retinal progenitor cell survival under hypoxic and superoxide stress. Mol. Cell. Neurosci. 2011, 47, 145-153.

201. Hou, G.; Xue, L.; Lu, Z.; Fan, T.; Tian, F.; Xue, Y. An activated mTOR/p70S6K signaling pathway in esophageal squamous cell carcinoma cell lines and inhibition of the pathway by rapamycin and siRNA against mTOR. Cancer Lett. 2007, 253, 236-248.

202. Zhang, D.; Contu, R.; Latronico, M.V.; Zhang, J.; Rizzi, R.; Catalucci, D.; Miyamoto, S.; Huang, K.; Ceci, M.; Gu, Y.; et al. MTORC1 regulates cardiac function and myocyte survival through 4E-BP1 inhibition in mice. J. Clin. Invest. 2010, 120, 2805-2816.

203. Dormond, O.; Madsen, J.C.; Briscoe, D.M. The effects of mTOR-Akt interactions on anti-apoptotic signaling in vascular endothelial cells. J. Biol. Chem. 2007, 282, 23679-23686.

204. Chong, Z.Z.; Li, F.; Maiese, K. The pro-survival pathways of mTOR and protein kinase B target glycogen synthase kinase-3beta and nuclear factor- $\mathrm{kB}$ to foster endogenous microglial cell protection. Int. J. Mol. Med. 2007, 19, 263-272. 
205. Choi, K.C.; Kim, S.H.; Ha, J.Y.; Kim, S.T.; Son, J.H. A novel mTOR activating protein protects dopamine neurons against oxidative stress by repressing autophagy related cell death. J. Neurochem. 2010, 112, 366-376.

206. Shang, Y.C.; Chong, Z.Z.; Wang, S.; Maiese, K. WNT1 inducible signaling pathway protein 1 (WISP1) targets PRAS40 to govern $\beta$-amyloid apoptotic injury of microglia. Curr. Neurovasc. Res. 2012, 9, 239-249.

207. Thedieck, K.; Polak, P.; Kim, M.L.; Molle, K.D.; Cohen, A.; Jeno, P.; Arrieumerlou, C.; Hall, M.N. PRAS40 and PRR5-like protein are new mTOR interactors that regulate apoptosis. PLoS One 2007, 2, e1217.

208. Chong, Z.Z.; Li, F.; Maiese, K. Attempted cell cycle induction in post-mitotic neurons occurs in early and late apoptotic programs through Rb, E2F1, and Caspase 3. Curr. Neurovasc. Res. 2006, 3, 25-39.

209. Yu, Y.; Ren, Q.G.; Zhang, Z.H.; Zhou, K.; Yu, Z.Y.; Luo, X.; Wang, W. Phospho-Rb mediating cell cycle reentry induces early apoptosis following oxygen-glucose deprivation in rat cortical neurons. Neurochem. Res. 2012, 37, 503-511.

210. Bhaskar, K.; Miller, M.; Chludzinski, A.; Herrup, K.; Zagorski, M.; Lamb, B.T. The PI3K-Akt-mTOR pathway regulates Abeta oligomer induced neuronal cell cycle events. Mol. Neurodegener. 2009, 4, 14.

211. Yu, L.; McPhee, C.K.; Zheng, L.; Mardones, G.A.; Rong, Y.; Peng, J.; Mi, N.; Zhao, Y.; Liu, Z.; Wan, F.; et al. Termination of autophagy and reformation of lysosomes regulated by mTOR. Nature 2010, 465, 942-946.

212. Rong, Y.; McPhee, C.K.; Deng, S.; Huang, L.; Chen, L.; Liu, M.; Tracy, K.; Baehrecke, E.H.; $\mathrm{Yu}$, L.; Lenardo, M.J. Spinster is required for autophagic lysosome reformation and mTOR reactivation following starvation. Proc. Natl. Acad. Sci. USA 2011, 108, 7826-7831.

213. Abdullah, A.; Wolfe, R.; Mannan, H.; Stoelwinder, J.U.; Stevenson, C.; Peeters, A. Epidemiologic merit of obese-years, the combination of degree and duration of obesity. Am. J. Epidemiol. 2012, 176, 99-107.

214. Reagan, L.P. Diabetes as a chronic metabolic stressor: Causes, consequences and clinical complications. Exp. Neurol. 2012, 233, 68-78.

215. Kelly, G.S. A review of the sirtuin system, its clinical implications, and the potential role of dietary activators like resveratrol: Part 2. Altern. Med. Rev. 2010, 15, 313-328.

216. Lai, C.S.; Tsai, M.L.; Badmaev, V.; Jimenez, M.; Ho, C.T.; Pan, M.H. Xanthigen suppresses preadipocyte differentiation and adipogenesis through down-regulation of PPARgamma and C/EBPs and modulation of SIRT-1, AMPK, and FoxO pathways. J. Agric. Food Chem. 2012, 60, 1094-1101.

217. Chong, Z.Z.; Maiese, K. Enhanced tolerance against early and late apoptotic oxidative stress in mammalian neurons through nicotinamidase and sirtuin mediated pathways. Curr. Neurovasc. Res. 2008, 5, 159-170.

218. Sun, C.; Zhang, F.; Ge, X.; Yan, T.; Chen, X.; Shi, X.; Zhai, Q. SIRT1 improves insulin sensitivity under insulin-resistant conditions by repressing PTP1B. Cell Metab. 2007, 6, 307-319. 
219. Li, Y.; Xu, S.; Giles, A.; Nakamura, K.; Lee, J.W.; Hou, X.; Donmez, G.; Li, J.; Luo, Z.; Walsh, K.; et al. Hepatic overexpression of SIRT1 in mice attenuates endoplasmic reticulum stress and insulin resistance in the liver. FASEB J. 2011, 25, 1664-1679.

220. Frojdo, S.; Durand, C.; Molin, L.; Carey, A.L.; El-Osta, A.; Kingwell, B.A.; Febbraio, M.A.; Solari, F.; Vidal, H.; Pirola, L. Phosphoinositide 3-kinase as a novel functional target for the regulation of the insulin signaling pathway by SIRT1. Mol. Cell. Endocrinol. 2011, 335, $166-176$.

221. Bordone, L.; Motta, M.C.; Picard, F.; Robinson, A.; Jhala, U.S.; Apfeld, J.; McDonagh, T.; Lemieux, M.; McBurney, M.; Szilvasi, A.; et al. Sirt1 regulates insulin secretion by repressing UCP2 in pancreatic beta cells. PLoS Biol. 2006, 4, e31.

222. Sundaresan, N.R.; Pillai, V.B.; Wolfgeher, D.; Samant, S.; Vasudevan, P.; Parekh, V.; Raghuraman, H.; Cunningham, J.M.; Gupta, M.; Gupta, M.P. The deacetylase SIRT1 promotes membrane localization and activation of Akt and PDK1 during tumorigenesis and cardiac hypertrophy. Sci. Signal. 2011, 4, doi:10.1126/scisignal.2001465.

223. Wang, F.; Chan, C.H.; Chen, K.; Guan, X.; Lin, H.K.; Tong, Q. Deacetylation of FOXO3 by SIRT1 or SIRT2 leads to Skp2-mediated FOXO3 ubiquitination and degradation. Oncogene 2012, 31, 1546-1557.

224. Wang, R.H.; Kim, H.S.; Xiao, C.; Xu, X.; Gavrilova, O.; Deng, C.X. Hepatic Sirt1 deficiency in mice impairs mTorc2/Akt signaling and results in hyperglycemia, oxidative damage, and insulin resistance. J. Clin. Invest. 2011, 121, 4477-4490.

225. Guo, W.; Qian, L.; Zhang, J.; Zhang, W.; Morrison, A.; Hayes, P.; Wilson, S.; Chen, T.; Zhao, J. Sirtl overexpression in neurons promotes neurite outgrowth and cell survival through inhibition of the mTOR signaling. J. Neurosci. Res. 2011, 89, 1723-1736.

226. Hamada, S.; Hara, K.; Hamada, T.; Yasuda, H.; Moriyama, H.; Nakayama, R.; Nagata, M.; Yokono, K. Upregulation of the mammalian target of rapamycin complex 1 pathway by Ras homolog enriched in brain in pancreatic beta-cells leads to increased beta-cell mass and prevention of hyperglycemia. Diabetes 2009, 58, 1321-1332.

227. Treins, C.; Alliouachene, S.; Hassouna, R.; Xie, Y.; Birnbaum, M.J.; Pende, M. The combined deletion of S6K1 and Akt2 deteriorates glycaemic control in high fat diet. Mol. Cell. Biol. 2012, 32, 4004-4011.

228. Fraenkel, M.; Ketzinel-Gilad, M.; Ariav, Y.; Pappo, O.; Karaca, M.; Castel, J.; Berthault, M.F.; Magnan, C.; Cerasi, E.; Kaiser, N.; et al. mTOR inhibition by rapamycin prevents beta-cell adaptation to hyperglycemia and exacerbates the metabolic state in type 2 diabetes. Diabetes 2008, 57, 945-957.

229. Cho, H.J.; Park, J.; Lee, H.W.; Lee, Y.S.; Kim, J.B. Regulation of adipocyte differentiation and insulin action with rapamycin. Biochem. Biophys. Res. Commun. 2004, 321, 942-948.

230. Yeh, W.C.; Bierer, B.E.; McKnight, S.L. Rapamycin inhibits clonal expansion and adipogenic differentiation of 3T3-L1 cells. Proc. Natl. Acad. Sci. USA 1995, 92, 11086-11090.

231. Chakrabarti, P.; English, T.; Shi, J.; Smas, C.M.; Kandror, K.V. Mammalian target of rapamycin complex 1 suppresses lipolysis, stimulates lipogenesis, and promotes fat storage. Diabetes $\mathbf{2 0 1 0}$, 59, 775-781. 
232. Rovira, J.; Marcelo Arellano, E.; Burke, J.T.; Brault, Y.; Moya-Rull, D.; Banon-Maneus, E.; Ramirez-Bajo, M.J.; Gutierrez-Dalmau, A.; Revuelta, I.; Quintana, L.F.; et al. Effect of mTOR inhibitor on body weight: From an experimental rat model to human transplant patients. Transpl. Int. 2008, 21, 992-998.

233. Phan, J.; Peterfy, M.; Reue, K. Lipin expression preceding peroxisome proliferator-activated receptor $\gamma$ is critical for adipogenesis in vivo and in vitro. J. Biol. Chem. 2004, 279, 29558-29564.

234. Peterfy, M.; Phan, J.; Xu, P.; Reue, K. Lipodystrophy in the fld mouse results from mutation of a new gene encoding a nuclear protein, lipin. Nat. Genet. 2001, 27, 121-124.

235. Finck, B.N.; Gropler, M.C.; Chen, Z.; Leone, T.C.; Croce, M.A.; Harris, T.E.; Lawrence, J.C., Jr.; Kelly, D.P. Lipin 1 is an inducible amplifier of the hepatic PGC-1alpha/PPARalpha regulatory pathway. Cell Metab. 2006, 4, 199-210.

236. Huffman, T.A.; Mothe-Satney, I.; Lawrence, J.C., Jr. Insulin-stimulated phosphorylation of lipin mediated by the mammalian target of rapamycin. Proc. Natl. Acad. Sci. USA 2002, 99, 1047-1052.

237. Cota, D.; Proulx, K.; Smith, K.A.; Kozma, S.C.; Thomas, G.; Woods, S.C.; Seeley, R.J. Hypothalamic mTOR signaling regulates food intake. Science 2006, 312, 927-930.

238. Cota, D.; Matter, E.K.; Woods, S.C.; Seeley, R.J. The role of hypothalamic mammalian target of rapamycin complex 1 signaling in diet-induced obesity. J. Neurosci. 2008, 28, 7202-7208.

239. Chakrabarti, P.; Anno, T.; Manning, B.D.; Luo, Z.; Kandror, K.V. The mammalian target of rapamycin complex 1 regulates leptin biosynthesis in adipocytes at the level of translation: The role of the 5'-untranslated region in the expression of leptin messenger ribonucleic acid. Mol. Endocrinol. 2008, 22, 2260-2267.

240. Inoki, K.; Zhu, T.; Guan, K.L. TSC2 mediates cellular energy response to control cell growth and survival. Cell 2003, 115, 577-590.

241. Chong, Z.Z.; Kang, J.Q.; Maiese, K. Apaf-1, Bcl-xL, Cytochrome c, and Caspase-9 form the critical elements for cerebral vascular protection by erythropoietin. J. Cereb. Blood Flow Metab. 2003, 23, 320-330.

242. Toba, H.; Kojima, Y.; Wang, J.; Noda, K.; Tian, W.; Kobara, M.; Nakata, T. Erythropoietin attenuated vascular dysfunction and inflammation by inhibiting NADPH oxidase-derived superoxide production in nitric oxide synthase-inhibited hypertensive rat aorta. Eur. J. Pharmacol. 2012, 691, 190-197.

243. Sheng, B.; Liu, J.; Li, G.H. Metformin preconditioning protects Daphnia pulex from lethal hypoxic insult involving AMPK, HIF and mTOR signaling. Comp. Biochem. Physiol. B Biochem. Mol. Biol. 2012, 163, 51-58.

244. Koh, P.O. Melatonin prevents ischemic brain injury through activation of the mTOR/p70S6 kinase signaling pathway. Neurosci. Lett. 2008, 444, 74-78.

245. Liu, G.; Detloff, M.R.; Miller, K.N.; Santi, L.; Houle, J.D. Exercise modulates microRNAs that affect the PTEN/mTOR pathway in rats after spinal cord injury. Exp. Neurol. 2012, 233, 447-456.

246. Walker, C.L.; Walker, M.J.; Liu, N.K.; Risberg, E.C.; Gao, X.; Chen, J.; Xu, X.M. Systemic bisperoxovanadium activates Akt/mTOR, reduces autophagy, and enhances recovery following cervical spinal cord injury. PLoS One 2012, 7, e30012. 
247. Hu, L.Y.; Sun, Z.G.; Wen, Y.M.; Cheng, G.Z.; Wang, S.L.; Zhao, H.B.; Zhang, X.R. ATP-mediated protein kinase B Akt/mammalian target of rapamycin mTOR/p70 ribosomal S6 protein p70S6 kinase signaling pathway activation promotes improvement of locomotor function after spinal cord injury in rats. Neuroscience 2010, 169, 1046-1062.

248. Sun, F.; Park, K.K.; Belin, S.; Wang, D.; Lu, T.; Chen, G.; Zhang, K.; Yeung, C.; Feng, G.; Yankner, B.A.; et al. Sustained axon regeneration induced by co-deletion of PTEN and SOCS3. Nature 2011, 480, 372-375.

249. Liu, K.; Lu, Y.; Lee, J.K.; Samara, R.; Willenberg, R.; Sears-Kraxberger, I.; Tedeschi, A.; Park, K.K.; Jin, D.; Cai, B.; et al. PTEN deletion enhances the regenerative ability of adult corticospinal neurons. Nat. Neurosci. 2010, 13, 1075-1081.

250. Park, K.K.; Liu, K.; Hu, Y.; Smith, P.D.; Wang, C.; Cai, B.; Xu, B.; Connolly, L.; Kramvis, I.; Sahin, M.; et al. Promoting axon regeneration in the adult CNS by modulation of the PTEN/mTOR pathway. Science 2008, 322, 963-966.

251. Erlich, S.; Alexandrovich, A.; Shohami, E.; Pinkas-Kramarski, R. Rapamycin is a neuroprotective treatment for traumatic brain injury. Neurobiol. Dis. 2007, 26, 86-93.

252. Sekiguchi, A.; Kanno, H.; Ozawa, H.; Yamaya, S.; Itoi, E. Rapamycin promotes autophagy and reduces neural tissue damage and locomotor impairment after spinal cord injury in mice. J. Neurotrauma 2012, 29, 946-956.

253. Shi, G.D.; OuYang, Y.P.; Shi, J.G.; Liu, Y.; Yuan, W.; Jia, L.S. PTEN deletion prevents ischemic brain injury by activating the mTOR signaling pathway. Biochem. Biophys. Res. Commun. 2011, 404, 941-945.

254. Zhang, W.; Khatibi, N.H.; Yamaguchi-Okada, M.; Yan, J.; Chen, C.; Hu, Q.; Meng, H.; Han, H.; Liu, S.; Zhou, C. Mammalian target of rapamycin (mTOR) inhibition reduces cerebral vasospasm following a subarachnoid hemorrhage injury in canines. Exp. Neurol. 2012, 233, 799-806.

255. Zeng, L.H.; Rensing, N.R.; Wong, M. The mammalian target of rapamycin signaling pathway mediates epileptogenesis in a model of temporal lobe epilepsy. J. Neurosci. 2009, 29, 6964-6972.

256. Buckmaster, P.S.; Ingram, E.A.; Wen, X. Inhibition of the mammalian target of rapamycin signaling pathway suppresses dentate granule cell axon sprouting in a rodent model of temporal lobe epilepsy. J. Neurosci. 2009, 29, 8259-8269.

257. Holmes, G.L.; Stafstrom, C.E. Tuberous sclerosis complex and epilepsy: Recent developments and future challenges. Epilepsia 2007, 48, 617-630.

258. Waltereit, R.; Welzl, H.; Dichgans, J.; Lipp, H.P.; Schmidt, W.J.; Weller, M. Enhanced episodic-like memory and kindling epilepsy in a rat model of tuberous sclerosis. J. Neurochem. 2006, 96, 407-413.

259. Zeng, L.H.; Xu, L.; Gutmann, D.H.; Wong, M. Rapamycin prevents epilepsy in a mouse model of tuberous sclerosis complex. Ann. Neurol. 2008, 63, 444-453.

260. Lee, S.T.; Chu, K.; Park, J.E.; Jung, K.H.; Jeon, D.; Lim, J.Y.; Lee, S.K.; Kim, M.; Roh, J.K. Erythropoietin improves memory function with reducing endothelial dysfunction and amyloid-beta burden in Alzheimer's disease models. J. Neurochem. 2012, 120, 115-124. 
261. Burgos-Ramos, E.; Martos-Moreno, G.A.; Lopez, M.G.; Herranz, R.; Aguado-Llera, D.; Egea, J.; Frechilla, D.; Cenarruzabeitia, E.; Leon, R.; Arilla-Ferreiro, E.; et al. The $N$-terminal tripeptide of insulin-like growth factor-I protects against beta-amyloid-induced somatostatin depletion by calcium and glycogen synthase kinase 3 beta modulation. J. Neurochem. 2009, 109, 360-370.

262. Echeverria, V.; Zeitlin, R.; Burgess, S.; Patel, S.; Barman, A.; Thakur, G.; Mamcarz, M.; Wang, L.; Sattelle, D.B.; Kirschner, D.A.; et al. Cotinine reduces amyloid-beta aggregation and improves memory in Alzheimer's disease mice. J. Alzheimers Dis. 2011, 24, 817-835.

263. Li, L.; Xu, B.; Zhu, Y.; Chen, L.; Sokabe, M. DHEA prevents Abeta25-35-impaired survival of newborn neurons in the dentate gyrus through a modulation of PI3K-Akt-mTOR signaling. Neuropharmacology 2010, 59, 323-333.

264. Chano, T.; Okabe, H.; Hulette, C.M. RB1CC1 insufficiency causes neuronal atrophy through mTOR signaling alteration and involved in the pathology of Alzheimer's diseases. Brain Res. 2007, 1168, 97-105.

265. Paccalin, M.; Pain-Barc, S.; Pluchon, C.; Paul, C.; Besson, M.N.; Carret-Rebillat, A.S.; Rioux-Bilan, A.; Gil, R.; Hugon, J. Activated mTOR and PKR kinases in lymphocytes correlate with memory and cognitive decline in Alzheimer's disease. Dementia Geriatr. Cognit. Disord. 2006, 22, 320-326.

266. Slipczuk, L.; Bekinschtein, P.; Katche, C.; Cammarota, M.; Izquierdo, I.; Medina, J.H. BDNF activates mTOR to regulate GluR1 expression required for memory formation. PLoS One 2009, 4, e6007.

267. Ma, T.; Hoeffer, C.A.; Capetillo-Zarate, E.; Yu, F.; Wong, H.; Lin, M.T.; Tampellini, D.; Klann, E.; Blitzer, R.D.; Gouras, G.K. Dysregulation of the mTOR pathway mediates impairment of synaptic plasticity in a mouse model of Alzheimer's disease. PLoS One 2010, $5, \mathrm{e} 12845$.

268. Lafay-Chebassier, C.; Paccalin, M.; Page, G.; Barc-Pain, S.; Perault-Pochat, M.C.; Gil, R.; Pradier, L.; Hugon, J. mTOR/p70S6k signalling alteration by A $\beta$ exposure as well as in APP-PS1 transgenic models and in patients with Alzheimer's disease. J. Neurochem. 2005, 94, 215-225.

269. Griffin, R.J.; Moloney, A.; Kelliher, M.; Johnston, J.A.; Ravid, R.; Dockery, P.; O'Connor, R.; O'Neill, C. Activation of Akt/PKB, increased phosphorylation of Akt substrates and loss and altered distribution of Akt and PTEN are features of Alzheimer's disease pathology. J. Neurochem. 2005, 93, 105-117.

270. Esteras, N.; Munoz, U.; Alquezar, C.; Bartolome, F.; Bermejo-Pareja, F.; Martin-Requero, A. Altered calmodulin degradation and signaling in non-neuronal cells from Alzheimer's disease patients. Curr. Alzheimer Res. 2012, 9, 267-277.

271. An, W.L.; Cowburn, R.F.; Li, L.; Braak, H.; Alafuzoff, I.; Iqbal, K.; Iqbal, I.G.; Winblad, B.; Pei, J.J. Up-regulation of phosphorylated/activated p70 S6 kinase and its relationship to neurofibrillary pathology in Alzheimer's disease. Am. J. Pathol. 2003, 163, 591-607.

272. Sarkar, S.; Ravikumar, B.; Rubinsztein, D.C. Autophagic clearance of aggregate-prone proteins associated with neurodegeneration. Methods Enzymol. 2009, 453, 83-110.

273. Berger, Z.; Ravikumar, B.; Menzies, F.M.; Oroz, L.G.; Underwood, B.R.; Pangalos, M.N.; Schmitt, I.; Wullner, U.; Evert, B.O.; O'Kane, C.J.; et al. Rapamycin alleviates toxicity of different aggregate-prone proteins. Hum. Mol. Genet. 2006, 15, 433-442. 
274. Ravikumar, B.; Vacher, C.; Berger, Z.; Davies, J.E.; Luo, S.; Oroz, L.G.; Scaravilli, F.; Easton, D.F.; Duden, R.; O’Kane, C.J.; et al. Inhibition of mTOR induces autophagy and reduces toxicity of polyglutamine expansions in fly and mouse models of Huntington disease. Nat. Genet. 2004, 36, 585-595.

275. Floto, R.A.; Sarkar, S.; Perlstein, E.O.; Kampmann, B.; Schreiber, S.L.; Rubinsztein, D.C. Small molecule enhancers of rapamycin-induced TOR inhibition promote autophagy, reduce toxicity in Huntington's disease models and enhance killing of mycobacteria by macrophages. Autophagy 2007, 3, 620-622.

276. Roscic, A.; Baldo, B.; Crochemore, C.; Marcellin, D.; Paganetti, P. Induction of autophagy with catalytic mTOR inhibitors reduces huntingtin aggregates in a neuronal cell model. J. Neurochem. 2011, 119, 398-407.

277. Fox, J.H.; Connor, T.; Chopra, V.; Dorsey, K.; Kama, J.A.; Bleckmann, D.; Betschart, C.; Hoyer, D.; Frentzel, S.; Difiglia, M.; et al. The mTOR kinase inhibitor Everolimus decreases S6 kinase phosphorylation but fails to reduce mutant huntingtin levels in brain and is not neuroprotective in the R6/2 mouse model of Huntington's disease. Mol. Neurodegener. 2010, 5, 26.

278. Crews, L.; Spencer, B.; Desplats, P.; Patrick, C.; Paulino, A.; Rockenstein, E.; Hansen, L.; Adame, A.; Galasko, D.; Masliah, E. Selective molecular alterations in the autophagy pathway in patients with Lewy body disease and in models of alpha-synucleinopathy. PLoS One 2010, 5, e9313.

279. Tain, L.S.; Mortiboys, H.; Tao, R.N.; Ziviani, E.; Bandmann, O.; Whitworth, A.J. Rapamycin activation of 4E-BP prevents parkinsonian dopaminergic neuron loss. Nat. Neurosci. 2009, 12, 1129-1135.

280. DeYoung, M.P.; Horak, P.; Sofer, A.; Sgroi, D.; Ellisen, L.W. Hypoxia regulates TSC1/2-mTOR signaling and tumor suppression through REDD1-mediated 14-3-3 shuttling. Genes Dev. 2008, 22, 239-251.

281. Malagelada, C.; Ryu, E.J.; Biswas, S.C.; Jackson-Lewis, V.; Greene, L.A. RTP801 is elevated in Parkinson brain substantia nigral neurons and mediates death in cellular models of Parkinson's disease by a mechanism involving mammalian target of rapamycin inactivation. J. Neurosci. 2006, 26, 9996-10005.

282. Imai, Y.; Gehrke, S.; Wang, H.Q.; Takahashi, R.; Hasegawa, K.; Oota, E.; Lu, B. Phosphorylation of 4E-BP by LRRK2 affects the maintenance of dopaminergic neurons in Drosophila. EMBO J. 2008, 27, 2432-2443.

283. Santini, E.; Heiman, M.; Greengard, P.; Valjent, E.; Fisone, G. Inhibition of mTOR signaling in Parkinson's disease prevents L-DOPA-induced dyskinesia. Sci. Signal. 2009, 2, doi: 10.1126/scisignal.2000308.

284. Fokas, E.; Yoshimura, M.; Prevo, R.; Higgins, G.; Hackl, W.; Maira, S.M.; Bernhard, E.J.; McKenna, W.G.; Muschel, R.J. NVP-BEZ235 and NVP-BGT226, dual phosphatidylinositol 3-kinase/Mammalian target of rapamycin inhibitors, enhance tumor and endothelial cell radiosensitivity. Radiat. Oncol. 2012, 7, 48.

285. Maiese, K.; Hou, J.; Chong, Z.Z.; Shang, Y.C. A fork in the path: Developing therapeutic inroads with FoxO proteins. Oxid. Med. Cell. Longev. 2009, 2, 119-129. 
286. Musteanu, M.; Blaas, L.; Zenz, R.; Svinka, J.; Hoffmann, T.; Grabner, B.; Schramek, D.; Kantner, H.P.; Muller, M.; Kolbe, T.; et al. A mouse model to identify cooperating signaling pathways in cancer. Nat. Methods 2012, 9, 897-900.

287. Pavel, M.E.; Hainsworth, J.D.; Baudin, E.; Peeters, M.; Horsch, D.; Winkler, R.E.; Klimovsky, J.; Lebwohl, D.; Jehl, V.; Wolin, E.M.; et al. Everolimus plus octreotide long-acting repeatable for the treatment of advanced neuroendocrine tumours associated with carcinoid syndrome (RADIANT-2): A randomised, placebo-controlled, phase 3 study. Lancet 2011, 378, 2005-2012.

288. Baryawno, N.; Sveinbjornsson, B.; Eksborg, S.; Chen, C.S.; Kogner, P.; Johnsen, J.I. Small-molecule inhibitors of phosphatidylinositol 3-kinase/Akt signaling inhibit Wnt/beta-catenin pathway cross-talk and suppress medulloblastoma growth. Cancer Res. 2010, 70, 266-276.

289. Majumder, S.; Richardson, A.; Strong, R.; Oddo, S. Inducing autophagy by rapamycin before, but not after, the formation of plaques and tangles ameliorates cognitive deficits. PLoS One 2011, 6, e25416.

290. Pattingre, S.; Tassa, A.; Qu, X.; Garuti, R.; Liang, X.H.; Mizushima, N.; Packer, M.; Schneider, M.D.; Levine, B. Bcl-2 antiapoptotic proteins inhibit Beclin 1-dependent autophagy. Cell 2005, 122, 927-939.

291. Carayol, N.; Vakana, E.; Sassano, A.; Kaur, S.; Goussetis, D.J.; Glaser, H.; Druker, B.J.; Donato, N.J.; Altman, J.K.; Barr, S.; et al. Critical roles for mTORC2- and rapamycin-insensitive mTORC1-complexes in growth and survival of BCR-ABL-expressing leukemic cells. Proc. Natl. Acad. Sci. USA 2010, 107, 12469-12474.

(C) 2012 by the authors; licensee MDPI, Basel, Switzerland. This article is an open access article distributed under the terms and conditions of the Creative Commons Attribution license (http://creativecommons.org/licenses/by/3.0/). 